\title{
Modification of Dietary Habits for Prevention of Gout in Japanese People: Gout and Food Intake
}

\author{
Takashi Koguchi \\ Department of Human Education, Kokugakuin Tochigi Junior College, Tochigi, Japan \\ Email address: \\ echo130@nifty.com \\ To cite this article: \\ Takashi Koguchi. Modification of Dietary Habits for Prevention of Gout in Japanese People: Gout and Food Intake. American Journal of \\ Health Research. Vol. 9, No. 5, 2021, pp. 158-175. doi: 10.11648/j.ajhr.20210905.15
}

Received: August 1, 2021; Accepted: September 1, 2021; Published: September 10, 2021

\begin{abstract}
In Japan, most of gout patients are adults, and the prevalence of gout has increased markedly since the 1960s. This phenomenon is thought to be attributed to the westernization of the Japanese diet since 1955. Monitoring the intake of nutrients and foods in Japanese people is essential in the prevention of gout. The objective of this article is to propose a preventive method for gout through the evaluation of recent dietary habits in Japanese people. In this article, the author shows the relationship between the number of gout patients and food intake in Japanese people and suggests modification of food intake for the prevention of gout in Japanese people referencing the results of clinical research reported. The author used the data of the Comprehensive Survey of Living Conditions in Japan for the number of gout patients (1986-2016) and the data of the National Health and Nutrition Survey in Japan (1946-2017) for the intake of foods. The relationship between the number of gout patients and food intake in Japanese people was examined. Modification of food intake for the prevention of gout is suggested as follows: limiting the intake of meat, organ meats high in purine content (e.g., liver, kidney), confectioneries (sugary foods including desserts and sweets), and sugar-sweetened beverages; limiting alcohol beverage consumption; limiting or decreasing intake of oils and fats, and seasonings and condiments (soy paste, soy sauce, and sauce); encourage intake of fiber-rich foods (e.g., cereals, whole grains, high-fiber bread), eggs, milk and dairy products (especially low-fat dairy products), legumes, seeds and nuts, fruit, vegetables, and coffee. The above dietary habits for the prevention of gout with proper choices of foods may also play a helpful role in the prevention of gout.
\end{abstract}

Keywords: Comorbidities of Gout, Dietary Habits, Food, Gout, Hyperuricemia, Nutrient, Uric Acid

\section{Introduction}

To explore means of the dietary control for the prevention of gout, the author [1-3] previously suggested modification of nutrient intake for the prevention of gout in Japanese people as described below: energy-providing nutrient balance (percentages of proteins, fats, and carbohydrates of total energy intake) should be within the range of the tentative dietary goal for preventing lifestyle-related diseases (DG); reduce fat (especially animal fat) intake and maintain the mean ratio of energy intake from saturated fatty acids in total energy intake (Saturated fatty acids/Energy) within the range of the tentative dietary goal for preventing lifestyle-related diseases (DG); replacement of saturated fatty acids with mono- and polyunsaturated ones (especially n-3 polyunsaturated fatty acids); avoidance of excessive intake of saturated fatty acids and cholesterol; limiting or decreasing salt intake; pay attention to sucrose and fructose intake; increase intake of dietary fiber, vitamin $A$, vitamin $B_{1}$, vitamin $\mathrm{B}_{2}$, vitamin $\mathrm{B}_{6}$, calcium, potassium, magnesium, and zinc; and maintenance of good hydration. Koguchi [4] reported the review that summarizes the results of clinical research (clinical trials and epidemiological studies) of the association between SUA concentration, hyperuricemia risk, or gout risk and dietary factors.

From the results of trends in food intake in Japanese people, it is necessary to recognize what food intake is important for the prevention of gout. This article shows the relationship between the number of gout patients and food intake in Japanese people and suggests modification of food intake for the prevention of gout in Japanese people referencing the results of clinical research reported. 


\section{Methods}

\subsection{The Number of Gout Patients}

The number of gout patients was estimated in the Comprehensive Survey of Living Conditions performed by the Ministry of Health, Labour and Welfare in Japan (1986-2016) [5]. The Comprehensive Survey of Living Conditions was based on self-reporting by residents. This article showed the rate of hospital visits due to gout from 1986 to 2016 based on the Comprehensive Survey of Living Conditions.

\subsection{The Trends in Nutrient or Food Intake in Japanese People}

The intake of nutrients or foods was searched in the National Health and Nutrition Survey Japan (1946-2017) performed by the Ministry of Health, Labour and Welfare in Japan [6-8].

Data were extracted from the series of Japanese National Nutrition Surveys that have been carried out every year throughout Japan since 1946 [8]. In these surveys, food consumption by families enrolled in the study was assessed by weighing food items consumed on three consecutive weekdays (until 1994) or one weekday (from 1995).

The daily nutrient or food intakes of Japanese people are shown as the mean values reported by the National Health and Nutrition Survey Japan (1946-2017) [6].

\subsection{Food Composition}

The food composition was extracted from a standard tables of food composition in Japan -2020- (Eighth Revised Edition) of the Council for Science and Technology, Ministry of Education, Culture, Sports, Science and Technology in Japan. The Ministry of Education, Culture, Sports, Science and Technology [9] and the National Institutes of Health in the U.S. Department of Health \& Human Services [10].

\subsection{Statistical Analysis}

The correlation efficient and the significance of the correlation between the number of gout patients and food intake in 1986, 1989, 1992, 1995, 1998, 2001, 2004, 2007, 2010, 2013, and 2016 were analyzed by Pearson Product Moment Correlation. A SigmaPlot 12.0 software program (version 12.0, Systat Software Inc, San Jose, CA) was used for statistical analysis. Differences were considered significant at $\mathrm{p}<0.05$.

\section{Relationship Between the Number of Gout Patients and Food Intake in Japanese People}

The results on the correlation between the number of gout patients and food intake in Japanese people are shown in Tables 1 and 2.
Table 1. Correlation between number of gout patients and intake of food group in Japanese people in 1986-2016.

\begin{tabular}{lcl}
\hline Food group & coefficient & p-value \\
\hline Grains & 0.813 & 0.00234 \\
Potatoes & -0.782 & 0.00450 \\
Mushrooms & 0.963 & 0.00000207 \\
Seaweed & 0.793 & 0.00360 \\
Animal products & -0.412 & 0.208 \\
Meat & 0.805 & 0.00280 \\
Seafood & -0.884 & 0.000308 \\
Eggs & -0.937 & 0.00000206 \\
Milk and dairy products & -0.0356 & 0.917 \\
Legumes & -0.726 & 0.0114 \\
Seeds and Nuts & 0.706 & 0.0151 \\
Fruit & -0.855 & 0.000805 \\
Vegetables & -0.0687 & 0.841 \\
Oils and Fats & -0.928 & 0.0000383 \\
Confectioneries & 0.711 & 0.0142 \\
Alcoholic Beverages & 0.861 & 0.000654 \\
\hline
\end{tabular}

Table 2. Correlation between number of gout patients and food item intake in Japanese people in 1986-2016.

\begin{tabular}{|c|c|c|}
\hline Food & coefficient & p-value \\
\hline \multicolumn{3}{|l|}{ Grains } \\
\hline Rice & 0.793 & 0.00358 \\
\hline Wheat processed foods & 0.864 & 0.000606 \\
\hline Breads & -0.616 & 0.0437 \\
\hline Rice processed foods & 0.280 & 0.405 \\
\hline \multicolumn{3}{|l|}{ Meat } \\
\hline Pork & 0.886 & 0.000284 \\
\hline Poultry & 0.838 & 0.00126 \\
\hline Ham and Sausage & 0.949 & 0.00000838 \\
\hline Beef & -0.629 & 0.0382 \\
\hline Wheal meat & -0.406 & 0.216 \\
\hline \multicolumn{3}{|l|}{ Seafood } \\
\hline Raw fish & -0.883 & 0.000311 \\
\hline Raw seafood & -0.894 & 0.000289 \\
\hline Shellfish & -0.710 & 0.0144 \\
\hline Seafood processed foods & -0.702 & 0.0161 \\
\hline \multicolumn{3}{|l|}{ Milk and dairy products } \\
\hline Cheese & 0.932 & 0.0000296 \\
\hline Milk & -0.901 & 0.000152 \\
\hline \multicolumn{3}{|l|}{ Legumes } \\
\hline $\begin{array}{l}\text { Soybeans and Soybeans processed } \\
\text { foods }\end{array}$ & -0.714 & 0.0135 \\
\hline Fermented soybean paste & -0.986 & 0.0000000279 \\
\hline Soybean curd (Tofu) & -0.210 & 0.536 \\
\hline \multicolumn{3}{|l|}{ Fruit } \\
\hline Citruses & -0.921 & 0.0000570 \\
\hline Apples & -0.918 & 0.0000674 \\
\hline Strawberries & -0.902 & 0.000147 \\
\hline \multicolumn{3}{|l|}{ Vegetables } \\
\hline Green and Yellow Vegetables & 0.356 & 0.283 \\
\hline Carrots & 0.507 & 0.112 \\
\hline Green Peppers & 0.460 & 0.155 \\
\hline Onions & 0.950 & 0.00000757 \\
\hline Cabbages & 0.737 & 0.00968 \\
\hline Tomatoes & 0.695 & 0.0175 \\
\hline Radishes & -0.857 & 0.000739 \\
\hline Cucumbers & -0.828 & 0.00166 \\
\hline Chinese cabbages & -0.640 & 0.0340 \\
\hline Spinach & -0.748 & 0.00813 \\
\hline Pickles & -0.971 & 0.000000702 \\
\hline \multicolumn{3}{|l|}{ Seasonings and Condiments } \\
\hline Salt* & -0.903 & 0.000141 \\
\hline Soy sauce & -0.905 & 0.000128 \\
\hline Sauce & -0.917 & 0.0000725 \\
\hline
\end{tabular}




\begin{tabular}{lll}
\hline Food & coefficient & p-value \\
\hline Mayonnaise & -0.898 & 0.000175 \\
Oils and Fats & & \\
Margarine & -0.850 & 0.000926 \\
Vegetable oils and fats & -0.856 & 0.000780 \\
Animal oils and fats & -0.643 & 0.0327 \\
Butter & -0.0445 & 0.897 \\
Confectioneries & & \\
Jam & 0.617 & 0.0433 \\
Alcoholic Beverages & & \\
Beer & 0.695 & 0.0175 \\
Rice Wine & -0.929 & 0.0000353 \\
Other Liquors & 0.967 & 0.00000126 \\
\hline
\end{tabular}

* Adapted from Koguchi [3].

\subsection{Grains}

The intake of total grains of Japanese people in 2016 was higher compared to that in 1986, 1989, 1992, 1995, and 1998 and was lower compared to that in 2001, 2004, 2007, 2010 and 2013 (1986: $307.3 \mathrm{~g} /$ day; 1989: $288.5 \mathrm{~g} /$ day; 1992: 284.9 g/day; 1995: $264.0 \mathrm{~g}$ /day; 1998: $257.9 \mathrm{~g} /$ day; 2001: 464.1 g/day; 2004: 449.5 g/day; 2007: 445.7 g/day; 2010: 439.7 g/day; 2013: $434.9 \mathrm{~g} /$ day; 2016: $422.1 \mathrm{~g} /$ day). The daily rice intake of Japanese people in 2016 was lower compared to that in 1957, 1961, and 1965 and was higher compared to that in 1971, 1975, 1980, and 1986 (1957: $354.7 \mathrm{~g}$ /day; 1961: 362.5 g/day; 1965: $349.8 \mathrm{~g} /$ day; 1971: $308.4 \mathrm{~g} /$ day; 1975: 248.3 g/day; 1980: 225.8 g/day; 1986: 212.1 g/day; 2016: 310.8 $\mathrm{g} /$ day). The daily wheat intake of Japanese people in 2016 was higher compared to that in 1957, 1961, 1965, 1971, 1975, 1980, and 1986 (1957: 56.9 g/day; 1961: 61.4 g/day; 1965: $60.4 \mathrm{~g} /$ day; 1971: $63.3 \mathrm{~g} /$ day; 1975: $90.2 \mathrm{~g} /$ day; 1980: 91.8 g/day; 1986: 93.7 g/day; 2016: 100.7 g/day). The Australian Dietary Guidelines [11] has proposed that the general recommended minimal intake of grain foods is 6 servings per day for a healthy $70-\mathrm{kg}$ man.

The daily intake of total grains, rice, wheat processed foods was positively correlated with the number of gout patients in 1986-2016, respectively (total grains: $r=0.813$, $\mathrm{p}=0.00234$; rice: $\mathrm{r}=0.793, \mathrm{p}=0.00358$; wheat processed foods: $\mathrm{r}=0.864, \mathrm{p}=0.000606$ ). Whereas the daily breads intake was negatively correlated with the number of gout patients in 1986-2016 $(\mathrm{r}=-0.616, \mathrm{p}=0.0437)$. The daily intake of rice processed foods and other grains did not show a significant correlation with the number of gout patients in 1986-2016, respectively (rice processed foods: $r=0.280, p=0.405$; other grains: $r=1.000 . p=0$ ). The daily total grains intake was negatively correlated with the number of gout patients in the adult population (aged $\geq 20$ years) in 2004-2016 ( $\mathrm{r}=-0.960$, $\mathrm{p}=0.00947$ ), and with the number of gout patients in adult men (aged $\geq 20$ years) in 2004-2016 $(\mathrm{r}=-0.981, \mathrm{p}=0.00325)$. Whereas the daily total grains intake did not show a significant correlation with the number of gout patients in adult women (aged $\geq 20$ years) in 2004-2016 ( $\mathrm{r}=0.731$, $\mathrm{p}=0.161$ ). This result suggests that the correlation of daily total grains intake with the number of gout patients tends to vary with gender.

In epidemiological studies, increased intake of bread and/or margarine (including low-fat margarine, i.e., $40 \%$ fat) [12, 13], high-fiber bread $[13,14]$, cereals $[13,14]$ was associated with decreased SUA concentrations. Higher intake of whole grains [15] and dietary fiber [16] was associated with decreased gout risk. Conscious intake of cereals, whole grains, and high-fiber bread seems to be important for the prevention of gout through reduced serum uric acid (SUA) concentrations.

In a randomized, crossover clinical trial in adult male subjects with risk factors for metabolic syndrome for 4 weeks, intake of rice endosperm protein (10 g/day) significantly decreased SUA concentrations compared with the casein group or the baseline [17]. Increase in intake of rice is important for a decrease in SUA concentrations.

\subsection{Potatoes, Mushrooms and Seaweed}

\subsubsection{Potatoes}

The daily potatoes intake of Japanese people in 2016 was lower compared to that in 1957, 1975, 1980, 1986, 1989, 1992, 1995, 1998, 2001, 2004, and 2007 and was higher compared to that in 1961, 1965, 1971, 2010, and 2013 (1957: $54.1 \mathrm{~g} /$ day; 1961: 51.6 g/day; 1965: 41.9 g/day; 1971: 38.8 g/day; 1975: 60.9 g/day; 1980: 63.4 g/day; 1986: 62.5 g/day; 1989: 65.3 g/day; 1992: 65.0 g/day; 1995: 68.9 g/day; 1998: 71.5 g/day; 2001: 63.0 g/day; 2004: 60.5 g/day; 2007: 56.3 g/day; 2010: $53.3 \mathrm{~g} /$ day; 2013: $52.6 \mathrm{~g} /$ day; 2016: $53.8 \mathrm{~g} /$ day).

The daily total potatoes intake was negatively correlated with the number of gout patients in 1986-2016 $(\mathrm{r}=-0.782$, $\mathrm{p}=0.00450$ ). The daily potato processed foods intake did not show a significant correlation with the number of gout patients in 1986-1998 $(\mathrm{r}=0.665, \mathrm{p}=0.221)$. The daily intake of potato plus potato processed foods and other potato plus potato processed foods was negatively correlated with the number of gout patients in 2001-2016, respectively (potato plus potato processed foods: $\mathrm{r}=-0.914, \mathrm{p}=0.0109$; other potato plus potato processed foods: $r=-0.837, p=0.0377$ ). The daily intake of sweet potato plus sweet potato processed foods did not show a significant correlation with the number of gout patients in 2001-2016 ( $\mathrm{r}=0.109, \mathrm{p}=0.838)$. The daily total potatoes intake did not show a significant correlation with the number of gout patients in the adult population (aged $\geq 20$ years) in 2004-2016 $(\mathrm{r}=-0.803, \mathrm{p}=0.102)$, with the number of gout patients in adult men (aged $\geq 20$ years) in 2004-2016 $(r=-0.860, p=0.0617)$, and with the number of gout patients in adult women (aged $\geq$ 20 years $)$ in 2004-2016 $(\mathrm{r}=0.836, \mathrm{p}=0.0778)$. This result suggests that the correlation of daily total potatoes intake with the number of gout patients tends to vary with gender.

Considering the data of mean ratio of energy intake from carbohydrate in total energy intake (Carbohydrate/Energy) and the daily dietary fiber, vitamin $\mathrm{A}$, vitamin $\mathrm{B}_{6}$, pantothenic acid, potassium, magnesium, phosphorus, iron intake, the daily potatoes intake seems to be appropriate or it seems better to increase it slightly.

\subsubsection{Mushrooms}

The mushroom intake of Japanese people in 2016 was higher compared to that in 1986, 1989, 1992, 1995, 1998, 2001, and 2004 and was lower compared to that in 2010 and 
2013 and was the same as that in 2007 (1986: $10.0 \mathrm{~g} / \mathrm{day} ; 1989$ : $10.2 \mathrm{~g} /$ day; 1992: $10.7 \mathrm{~g} /$ day; 1995: $11.8 \mathrm{~g} /$ day; 1998: 14.0 g/day; 2001: 14.9 g/day; 2004: 15.0 g/day; 2007: 16.0 g/day; 2010: $16.8 \mathrm{~g} /$ day; 2013: $16.6 \mathrm{~g} /$ day; 2016: $16.0 \mathrm{~g} /$ day).

The daily mushroom intake was positively correlated with the number of gout patients in 1986-2016 ( $\mathrm{r}=0.963$, $\mathrm{p}=0.00000207)$. The daily mushroom intake did not show a significant correlation with the number of gout patients in the adult population (aged $\geq 20$ years) in 2004-2016 ( $\mathrm{r}=0.346$, $\mathrm{p}=0.568$ ), and with the number of gout patients in adult men (aged $\geq 20$ years) in 2004-2016 $(r=0.256, p=0.677)$. The daily mushroom intake was negatively correlated with the number of gout patients in adult women (aged $\geq 20$ years) in $2004-2016(r=-0.906, p=0.0342)$. This result suggests that the correlation of daily mushroom intake with the number of gout patients tends to vary with gender and is stronger in adult women than in adult men.

Though mushrooms excluding shiitake mushrooms, king trumpet mushrooms, nameko mushrooms are high in purine, increased mushroom intake was associated with reduced serum uric acid (SUA) concentrations [18] and decreased hyperuricemia risk [19]. Considering the daily dietary fiber, vitamin $D$, vitamin $B_{1}$, vitamin $B_{2}$, pantothenic acid, folate, potassium, iron, zinc intake, the daily mushroom intake seems to be appropriate or it seems better to increase.

\subsubsection{Seaweed}

The daily seaweed intake of Japanese people in 2016 was higher compared to that in 1957, 1961, 1965, 1971, 1975, 1980, 1986, 1989, 1992, 1995, 1998, and 2013 and was lower compared to that in 2001, 2004, 2007, and 2010 (1957: 6.2 g/day; 1961: 5.0 g/day; 1965: 6.1 g/day; 1971: 6.8 g/day; 1975: $4.9 \mathrm{~g} /$ day; 1980: $5.1 \mathrm{~g} /$ day; 1986: $5.5 \mathrm{~g} /$ day; 1989: $5.8 \mathrm{~g} /$ day; 1992: $5.6 \mathrm{~g} /$ day; 1995: $5.3 \mathrm{~g} /$ day; 1998: $6.0 \mathrm{~g} /$ day; 2001: 13.5 g/day; 2004: 12.9 g/day; 2007: 11.4 g/day; 2010: 11.0 g/day; 2013: $10.2 \mathrm{~g} /$ day; 2016: $10.9 \mathrm{~g} /$ day).

The daily seaweed intake was positively correlated with the number of gout patients in 1986-2016 $(\mathrm{r}=0.793, \mathrm{p}=0.00360)$. The daily seaweed intake did not show a significant correlation with the number of gout patients in the adult population (aged $\geq 20$ years) in 2004-2016 ( $\mathrm{r}=-0.701$, $\mathrm{p}=0.187$ ), with the number of gout patients in adult men (aged $\geq 20$ years) in 2004-2016 ( $\mathrm{r}=-0.657, \mathrm{p}=0.228)$, and with the number of gout patients in adult women (aged $\geq 20$ years) in 2004-2016 ( $\mathrm{r}=0.659, \mathrm{p}=0.227)$. This result suggests that the correlation of daily seaweed intake with the number of gout patients tends to vary with gender.

Though seaweed (e.g., nori, wakame) are high in purine, increased seaweed intake was associated with decreased serum uric acid (SUA) concentrations in an epidemiological study [18]. Considering the daily dietary fiber, vitamin A, vitamin $B_{2}$, vitamin $B_{6}$, folate, vitamin $C$, magnesium, iron, zinc intake, the daily seaweed intake seems to be appropriate or it seems better to increase.

\subsubsection{Potatoes, Mushrooms and Seaweed}

The Dietary guidelines for Japanese (the Japanese food guide spinning top) by Ministry of Health, Labour and
Welfare and Ministry of Agriculture, Forestry and Fisheries has recommended that the daily total intake of potatoes, mushrooms and seaweed must be 1-2 servings (approximately 70-140 g), depending on an individual's caloric intake [20]. The daily total intake of potatoes, mushrooms and seaweed of Japanese people in 2016 was $80.7 \mathrm{~g}$. The daily total intake of potatoes, mushrooms and seaweed of Japanese people seems to be appropriate or it seems better to increase not to reach approximately $140 \mathrm{~g}$.

\subsection{Animal Products}

The intake of total animal products of Japanese people in 2016 was higher compared to that in 1986, 2007, 2010, and 2013 and was lower compared to that in 1989, 1992, 1995, 1998, 2001, and 2004 (1986: $321.9 \mathrm{~g} /$ day; 1989: $344.6 \mathrm{~g} /$ day; 1992: $345.3 \mathrm{~g} /$ day; 1995: $366.8 \mathrm{~g} /$ day; 1998: $350.0 \mathrm{~g} /$ day; 2001: $378.5 \mathrm{~g} /$ day; 2004: $331.4 \mathrm{~g} /$ day; 2007: $323.5 \mathrm{~g} /$ day; 2010: $308.2 \mathrm{~g}$ /day; 2013: $323.2 \mathrm{~g} /$ day; 2016: $329.7 \mathrm{~g} /$ day). The daily total animal products intake did not show a significant correlation with the number of gout patients in 1986-2016 $(r=-0.412, p=0.208)$. The daily viscera intake did not show a significant correlation with the number of gout patients in 2001-2016 $(\mathrm{r}=-0.401, \mathrm{p}=0.430)$.

\subsection{Meat}

The daily meat intake of Japanese people in 2016 was higher compared to that in 1957, 1961, 1965, 1971, 1975, 1980, 1986, 1989, 1992, 1995, 1998, 2001, 2004, 2007, 2010, and 2013 (1957: $12.7 \mathrm{~g} /$ day; 1961: $18.9 \mathrm{~g} /$ day; 1965: 29.5 g/day; 1971: 47.0 g/day; 1975: 64.2 g/day; 1980: 67.9 g/day; 1986: 70.8 g/day; 1989: 75.2 g/day; 1992: 75.1 g/day; 1995 : 82.3 g/day; 1998: 77.5 g/day; 2001: 76.3 g/day; 2004: 77.9 g/day; 2007: 82.6 g/day; 2010: 82.5 g/day; 2013: 89.6 g/day; 2016: $95.5 \mathrm{~g} /$ day).

The daily intake of total meat, pork, poultry, ham and sausage was positively correlated with the number of gout patients in 1986-2016, respectively (total meat: $r=0.805$, $\mathrm{p}=0.00280$; pork: $\mathrm{r}=0.886, \mathrm{p}=0.000284$; poultry: $\mathrm{r}=0.838$, $\mathrm{p}=0.00126$; ham and sausage: $\mathrm{r}=0.949, \mathrm{p}=0.00000838$ ). Whereas the daily beef intake was negatively correlated with the number of gout patients in 1986-2016 ( $\mathrm{r}=-0.629$, $\mathrm{p}=0.0382$ ). The daily wheal meat intake did not show a significant correlation with the number of gout patients in 1986-2016 $(\mathrm{r}=-0.406, \mathrm{p}=0.216)$. The daily total meat intake was positively correlated with number of gout patients in the adult population (aged $\geq 20$ years) in 2004-2016 ( $\mathrm{r}=0.939$, $\mathrm{p}=0.0181$ ), and with the number of gout patients in adult men (aged $\geq 20$ years) in 2004-2016 $(\mathrm{r}=0.939, \mathrm{p}=0.0179)$. The daily total meat intake did not show a significant correlation with the number of gout patients in adult women (aged $\geq 20$ years $)$ in 2004-2016 $(\mathrm{r}=-0.553, \mathrm{p}=0.333)$. This result suggests that the correlation of daily meat intake with the number of gout patients tends to vary with gender and is stronger in adult men than in adult women.

Meat intake increased plasma uric acid (PUA) or serum uric acid (SUA) concentrations in normal human subjects [21]. In 
epidemiological studies, increased meat intake was associated with increased SUA concentrations [12-14, 18, 22-27], hyperuricemia risk [19, 26, 28-33], and gout risk [15, 18, 22, $25,28,34-36]$. In a prospective cohort study, higher intake of red meat and poultry was associated with increased gout risk [37]. Consumption of red meat is low, because limiting intake of red meat would reduce SUA levels [38]. Excessive intake of meat was associated with increased risk of gout attacks [39, 40]. These results suggest that decrease in daily meat intake in Japanese people is essential for the prevention and suppression of gout.

The guidelines recommended the following for meat intake in patients with gout: (1) avoidance of excessive intake of meat [41]; (2) reduce red meat intake and avoiding offal intake [42]; and (3) limit purine-rich meat intake and avoidance of organ meats high in purine content (e.g., sweetbreads, liver, kidney) [43].

The highest quartile of red and processed meat intake was associated with a $22 \%$ higher risk of chronic kidney disease (CKD) compared with those with the lowest quartile in an analysis of the Atherosclerosis Risk in Communities study [44]. High red and processed meat intake was adversely associated with kidney disease risk [45].

\subsection{Seafood}

The daily total seafood (fish and shellfish) intake of Japanese people in 2016 was lower compared to that in 1957, 1961, 1965, 1971, 1975, 1980, 1986, 1989, 1992, 1995, 1998, 2001, 2004, 2007, 2010, and 2013 (1957: 71.6 g/day; 1961: $72.1 \mathrm{~g} /$ day; 1965: $76.3 \mathrm{~g} /$ day; 1971: $84.2 \mathrm{~g} /$ day; 1975: 94.0 g/day; 1980: 92.5 g/day; 1986: 90.5 g/day; 1989: 96.2 g/day; 1992: 96.8 g/day; 1995: 96.9 g/day; 1998: 95.9 g/day; 2001: 94.0 g/day; 2004: 82.6 g/day; 2007: 80.2 g/day; 2010: 72.5 g/day; 2013: $72.8 \mathrm{~g} /$ day; 2016: $65.6 \mathrm{~g} /$ day).

The daily intake of total seafood, raw fish, raw seafood, shellfish, seafood processed foods was negatively correlated with the number of gout patients in 1986-2016, respectively (total seafood: $\mathrm{r}=-0.884, \mathrm{p}=0.000308$; raw fish: $\mathrm{r}=-0.883$, $\mathrm{p}=0.000311$; raw seafood; $\mathrm{r}=-0.894, \mathrm{p}=0.000289$; shellfish: $\mathrm{r}=-0.710, \mathrm{p}=0.0144$; seafood processed foods: $\mathrm{r}=-0.702$, $\mathrm{p}=0.0161$ ). The daily intake of shrimp and crab, squid and octopus was negatively correlated with the number of gout patients in 2001-2016, respectively (shrimp and crab: $\mathrm{r}=$ $-0.967, \mathrm{p}=0.00196$; squid and octopus: $\mathrm{r}=-0.969, \mathrm{p}=0.00146$ ). The daily squid, octopus and crab intake did not show a significant correlation with the number of gout patients in 1986-1998 ( $r=-0.357, p=0.556)$. The daily total seafood intake was negatively correlated with the number of gout patients in the adult population (aged $\geq 20$ years) in 2004-2016 $(\mathrm{r}=-0.914, \mathrm{p}=0.0299)$, and with the number of gout patients in adult men (aged $\geq 20$ years) in 2004-2016 ( $\mathrm{r}=-0.952$, $\mathrm{p}=0.0126$ ). Whereas the daily total seafood intake was tended to be positively correlated with the number of gout patients in adult women (aged $\geq 20$ years) in 2004-2016 ( $\mathrm{r}=0.872$, $\mathrm{p}=0.0536$ ). This result suggests that the correlation of daily total seafood intake with the number of gout patients varies with gender and is stronger in adult men than in adult women.
Fish intake increased plasma uric acid (PUA) or serum uric acid (SUA) concentrations in normal human subjects [21]. In epidemiological studies, increased intake of seafood (including fish and shellfish) was associated with increased SUA concentrations [12, 22, 26, 27], hyperuricemia risk [26, 28, 29, 31, 33, 46-49], and gout risk [22, 28, 36, 37]. These results suggest that decrease in daily seafood (including fish and shellfish) intake in Japanese people is essential for the prevention of gout. Intake of shrimp and shell, which are purine-rich foods, in hyperuricemic patients was an independent risk factor for gout development from hyperuricemia [50].

The guidelines recommended the following for seafood intake in patients with gout: (1) avoidance of excessive intake of seafood [41]; (2) avoidance of intake of offal and shellfish [42]; and (3) limit purine-rich seafood intake and avoidance of organ meats high in purine content (e.g., sweetbreads, liver, kidney) [43].

Hisatome et al. [51] have recommended that intake of fish, shellfish, prawn and shrimp, and crab per one serving should be $80 \mathrm{~g}$ and $\leq 60 \mathrm{~g}, \leq 50 \mathrm{~g}$, and $100 \mathrm{~g}$, respectively. The daily total seafood (fish and shellfish) intake of Japanese people in 2016 (65.6 g/day) was less than the recommended intake of fish or crab per one serving by Hisatome et al. [51]. From the data of food composition [9, 10], it is important for Japanese people to eat seafood to take in more vitamin $A$, vitamin $D$, vitamin $\mathrm{B}_{1}$, vitamin $\mathrm{B}_{2}$, vitamin $\mathrm{B}_{6}$, pantothenic acid, folate, calcium, potassium, magnesium, phosphorus, iron, and zinc. Guidelines have recommended that eating foods rich in long-chain n-3 polyunsaturated fatty acids, such as fatty fish, which contains eicosapentaenoic acid (EPA) and docosahexaenoic acid (DHA), is recommended to prevent or treat cardiovascular disease (CVD) [52, 53]. Terkeltaub and Edwards [54] have stated that seafood (especially shellfish and crustaceans) consumption for hyperuricemia and gout patients should be $\leq 6 \mathrm{oz}(170 \mathrm{~g})$ per day as a starting point. Though higher intake of seafood was associated with increased gout risk [22, 28, 36], daily seafood (especially fish and fatty fish) intake reaching $80 \mathrm{~g}$ seems to be needed, as Hisatome et al. [51] have recommended.

\subsection{Eggs}

The daily egg intake of Japanese people in 2016 was higher compared to that in 1957, 1961, 1965, 2004, 2010, and 2013 and was lower compared to that in 1971, 1975, 1980, 1986, $1989,1992,1995,1998$, and 2001 and was the same as that in 2007 (1957: 14.2 g/day; 1961: 24.5 g/day; 1965: 35.2 g/day; 1971: 43.0 g/day; 1975: 41.5 g/day; 1980: 37.7 g/day; 1986: $41.2 \mathrm{~g} /$ day; 1989: $43.6 \mathrm{~g} /$ day; 1992: $43.3 \mathrm{~g} /$ day; 1995: 42.1 g/day; 1998: 40.5 g/day; 2001: 36.8 g/day; 2004: 34.4 g/day; 2007: 35.6 g/day; 2010: 34.8 g/day; 2013: 33.9 g/day; 2016: $35.6 \mathrm{~g} /$ day).

The daily egg intake was negatively correlated with the number of gout patients in 1986-2016 ( $\mathrm{r}=-0.937$, $\mathrm{p}=0.00000206$ ). The daily egg intake did not show a significant correlation with the number of gout patients in the adult population (aged $\geq 20$ years) in 2004-2016 ( $\mathrm{r}=0.317$, 
$\mathrm{p}=0.604)$, with the number of gout patients in adult men (aged $\geq 20$ years $)$ in $2004-2016(\mathrm{r}=0.235, \mathrm{p}=0.704)$, and with the number of gout patients in adult women (aged $\geq 20$ years) in 2004-2016 ( $\mathrm{r}=-0.648, \mathrm{p}=0.237)$.

In epidemiological studies, increased egg intake was associated with decreased serum uric acid (SUA) concentrations [13, 18] and hyperuricemia risk [55]. This result suggests that increase in daily egg intake in Japanese people is essential for the prevention of gout through reduced SUA concentrations and decreased hyperuricemia risk. Considering the mean ratio of energy intake from protein in total energy intake (Protein/Energy) and the daily vitamin A, vitamin $\mathrm{D}$, vitamin $\mathrm{B}_{1}$, pantothenic acid, folate, phosphorus, iron intake, the daily egg intake seems to be appropriate or it seems better to increase it slightly.

\subsection{Milk and Dairy Products}

The daily milk and dairy product intake of Japanese people in 2016 was higher compared to that in $1957,1961,1965$, 1971, 1975, 1980, 1986, 1989, 1992, 2007, 2010, and 2013 and was lower compared to that in 1995, 1998, 2001, and 2004 (1957: $19.7 \mathrm{~g} /$ day; 1961: $38.6 \mathrm{~g} /$ day; 1965: $57.4 \mathrm{~g} /$ day; 1971: 86.2 g/day; 1975: 103.6 g/day; 1980: $115.2 \mathrm{~g} /$ day; 1986: 117.9 g/day; 1989: $128.4 \mathrm{~g} /$ day; 1992: $118.1 \mathrm{~g} /$ day; 1995: 144.5 g/day; 1998: $135.0 \mathrm{~g} /$ day; 2001: $170.0 \mathrm{~g} /$ day; 2004: 135.4 g/day; 2007: 123.9 g/day; 2010: 117.3 g/day; 2013: 125.8 g/day; 2016: $131.8 \mathrm{~g} /$ day).

The daily cheese intake was positively correlated associated with the number of gout patients in 1986-2016 ( $\mathrm{r}=0.932$, $\mathrm{p}=0.0000296$ ). Whereas the daily milk intake was negatively correlated with the number of gout patients in 1986-2016 (r= -0.901, $\mathrm{p}=0.000152$ ). The daily milk and dairy product intake did not show a significant correlation with the number of gout patients in 1986-2016 ( $\mathrm{r}=-0.0356, \mathrm{p}=0.917)$. The daily yoghurt and fermented milk drink intake was positively correlated with the number of gout patients in 2001-2016 $(\mathrm{r}=0.890, \mathrm{p}=0.0175)$. The daily milk and dairy product intake did not show a significant correlation with the number of gout patients in the adult population (aged $\geq 20$ years) in 2004-2016 $(\mathrm{r}=0.687, \mathrm{p}=0.200)$, with the number of gout patients in adult men (aged $\geq 20$ years) in 2004-2016 $(\mathrm{r}=0.625, \mathrm{p}=0.260)$, and with the number of gout patients in adult women (aged $\geq 20$ years $)$ in 2004-2016 $(\mathrm{r}=-0.0159, \mathrm{p}=0.980)$.

Milk [56] and dairy products [56-60] decreased serum uric acid (SUA) concentrations. In epidemiological studies, increased intake of dairy products was associated with decreased SUA concentrations [12-14, 18, 23, 24, 26, 58, 61] and hyperuricemia risk [18, 26, 28, 35, 61]. This result suggests that increase in daily dairy product intake in Japanese people is essential for the prevention of gout through reduced SUA concentrations and decreased hyperuricemia risk.

The ingestion of milk proteins (casein, lactalbumin) and orotic acid has been shown to exert a uricosuric effect in healthy subjects [62]. Milk ingested promote renal oxypurine excretion, thereby reducing the availability of precursor substrates necessary for urate production $[56,59,63]$.

In a randomized controlled trial, skimmed milk powder derivatives (glycomacropeptide and G600 milk fat extract) have anti-inflammatory effects against acute gout flares [64]. Skim milk enriched with glycomacropeptide and G600 milk fat extract found a small reduction in the frequency of gout flares $[62,64]$. The use of skimmed milk powder enriched with two dairy fractions (glycomacropeptide and G600 fat extract) did not result in a reduction in frequency of acute gout flares when standard skimmed milk or lactose powder [64].

High low-fat dairy product intake was associated with reduced risk for kidney disease [45].

The guidelines recommended the following for dairy product intake: (1) encourage intake of low-fat dairy products or nonfat dairy products for patients with gout [41-43]; and (2) active intake of low-fat dairy products for patients with hypertension [65].

The Ministry of Health, Labour and Welfare in Japan has recommended that the daily dairy product intake must be 130 g or more [7]. The Dietary guidelines for Japanese (The Japanese food guide spinning top) has recommended that the daily consumption of milk and milk products must be 2-3 servings (milk: approximately $100 \mathrm{~g} /$ serving; yogurt: approximately $83 \mathrm{~g}$ /serving; cheese: approximately 20 $\mathrm{g} /$ serving), depending on an individual's caloric intake [20]. The daily milk and dairy product intake of Japanese people in 2016 was $131.8 \mathrm{~g}$. The daily milk and dairy product intake did not show a significant correlation with the number of gout patients in 1986-2016 ( $\mathrm{r}=-0.0356, \mathrm{p}=0.917)$. Higher intake of dairy products [28, 34-36] and low-fat dairy products [15] was associated with decreased gout risk. This result suggests that increase in daily intake of milk and dairy products (especially low-fat dairy products) in Japanese people is essential for the prevention of gout. Considering the result from the balance of the caloric ratio of protein, fat and carbohydrate in Japanese people in 2016 (protein: $14.8 \%$, fat: $27.4 \%$, and carbohydrates: $57.8 \%$ ) and the daily vitamin $A$, vitamin $D$, vitamin $B_{1}$, vitamin $\mathrm{B}_{2}$, vitamin $\mathrm{B}_{6}$, pantothenic acid, folic acid, calcium, magnesium, phosphorus, iron, zinc, purine intake, it seems better to increase the daily intake of milk and dairy products (especially low-fat dairy products).

\subsection{Legumes}

The daily intake of total legumes of Japanese people in 2016 was lower compared to that in 1957, 1961, 1965, 1971, 1975, 1980, 1986, 1989, 1992, 1995, 1998, 2004, and 2013 and was higher compared to that in 2001, 2007, and 2010 (1957: 61.6 g/day; 1961: $61.3 \mathrm{~g} /$ day; 1965: $64.3 \mathrm{~g} /$ day; 1971: $67.0 \mathrm{~g} /$ day; 1975: 70.0 g/day; 1980: 65.4 g/day; 1986: $65.3 \mathrm{~g} /$ day; 1989: 68.1 g/day; 1992: $67.5 \mathrm{~g} /$ day; 1995: $70.0 \mathrm{~g} /$ day; 1998: 72.5 g/day; 2001: 57.2 g/day; 2004: 61.5 g/day; 2007: 56.0 g/day; 2010: $55.3 \mathrm{~g} /$ day; 2013: $60.4 \mathrm{~g} /$ day; 2016: $58.6 \mathrm{~g} /$ day).

The daily intake of total legumes, soybeans and soybean processed foods, fermented soybean paste, other legumes was negatively correlated with the number of gout patients in 1986-2016, respectively (total legumes: $r=-0.726, p=0.0114$; soybeans and soybeans processed foods: $r=-0.714, p=0.0135$ : fermented soybean paste: $\mathrm{r}=-0.986, \mathrm{p}=0.0000000279$; other legumes: $r=-0.749, p=0.00802$ ). The daily soybean curd (tofu) 
intake did not show a significant correlation with the number of gout patients in 1986-2016 $(\mathrm{r}=-0.210, \mathrm{p}=0.536)$. The daily intake of deep-fried tofu, natto, deep-fried tofu plus natto did not show a significant correlation with the number of gout patients in 2001-2016, respectively (deep-fried tofu: $r=-0.183$, $\mathrm{p}=0.728$; natto: $\mathrm{r}=0.734, \mathrm{p}=0.0967$; deep-fried tofu plus natto: $\mathrm{r}=0.532, \mathrm{p}=0.278$ ). The daily intake of tofu processed foods did not show a significant correlation with the number of gout patients in 1986-1998 $(\mathrm{r}=-0.568, \mathrm{p}=0.318)$. The daily intake of total legumes did not show a significant correlation with the number of gout patients in the adult population (aged $\geq 20$ years $)$ in 2004-2016 ( $\mathrm{r}=0.143, \mathrm{p}=0.819)$, with the number of gout patients in adult men (aged $\geq 20$ years) in 2004-2016 $(\mathrm{r}=0.325, \mathrm{p}=0.594)$, and with the number of gout patients in adult women (aged $\geq 20$ years) in 2004-2016 ( $\mathrm{r}=0.674$, $\mathrm{p}=0.212$ ).

Common beans, broad bean seeds, soybeans and soy products (soy paste, soy bacon, soy flour, soy meat, soy tempe, tofu) contain polyphenols that suppress uric acid (UA) production by inhibition of xanthine oxidase activity [66]. In epidemiological studies, increased intake of legumes was associated with decreased serum uric acid (SUA) concentrations [18, 23] and hyperuricemia risk [33]. There was no increased risk of gout associated with the intake of legumes [35].

Intake of soy [21, 56, 63] and tofu [67] increased postprandial plasma UA (PUA) or SUA concentrations. Difference of effect of soy and tofu on postprandial SUA concentrations in healthy and gouty subjects was largely influenced by the content of protein and purine [67]. On the other hand, in epidemiological studies, increased intake of soy and soy products was associated with decreased hyperuricemia risk [19, 28, 46, 48, 68]. Soy promotes renal oxypurine excretion, thereby reducing the availability of precursor substrates necessary for urate production [63]. These results suggest that increase in daily intake of legumes and soy products in Japanese people is essential for the prevention of gout through reduced SUA concentrations and decreased hyperuricemia risk.

Legume intake was inversely associated with serum concentrations of inflammatory biomarkers [high sensitive C-reactive protein (hs-CRP), tumor necrosis factor-alpha (TNF- $\alpha$ ), and interleukin-6 (IL-6)] in a cross-sectional study among Iranian women [69]. Bitzer et al. [70] have stated that soy may prevent gout through the anti-inflammatory pathway, as a mouse study found that soy protein concentrates lower the nucleotide-binding and oligomerization domain-like receptor, leucine-rich repeat and pyrin domain-containing 3 (NLRP3) inflammasome and caspase-1 enzyme activity.

High intake of legumes was associated with reduced risk for kidney disease [45] Legume consumption was inversely associated with risk of coronary heart disease (CHD) and cardiovascular disease (CVD) [71, 72]. Legume consumption 4 times or more per week compared with less than once a week was associated with a $22 \%$ lower risk of CHD and an $11 \%$ lower risk of CVD [72].

The 2020 International Society of Hypertension global hypertension practice guidelines [73] has encouraged intake of legumes and tofu for patients with hypertension.

The daily intake of total legumes of Japanese people in 2016 was 58.6 g. The Ministry of Health, Labour and Welfare in Japan has recommended an intake of legumes of $100 \mathrm{~g}$ or more per day [7]. Higher intake of legumes [36, 37], non-soy legumes [37], soy foods [28, 37], legumes and nuts [15] was associated with decreased gout risk. This result suggests that increase in daily intake of legumes and soy foods in Japanese people is essential for the prevention of gout. Considering the result from the balance of the caloric ratio of protein, fat and carbohydrate in Japanese people in 2016 (protein: 14.8\%, fat: $27.4 \%$, and carbohydrates: $57.8 \%$ ) and the daily dietary fiber, vitamin $A$, vitamin $B_{1}$, vitamin $B_{2}$, vitamin $B_{6}$, pantothenic acid, folate, potassium, magnesium, phosphorus, zinc intake, it seems better to increase the daily intake of legumes for the prevention of gout.

\subsection{Seeds and Nuts}

The intake of seeds and nuts of Japanese people in 2016 was higher compared to that in 1986, 1989, 1992, 1995, 1998, 2001, 2004, 2007, 2010, and 2013 (1986: $1.7 \mathrm{~g}$ /day; 1989: 1.6 g/day; 1992: 1.5 g/day; 1995: 2.1 g/day; 1998: 2.1 g/day; 2001 2.2 g/day; 2004: $2.1 \mathrm{~g} /$ day; 2007: 2.0 g/day; 2010: $2.1 \mathrm{~g} /$ day; 2013: $1.9 \mathrm{~g} /$ day; 2016: $2.5 \mathrm{~g} /$ day).

The daily intake of seeds and nuts was positively correlated with the number of gout patients in 1986-2016 ( $\mathrm{r}=0.706$, $\mathrm{p}=0.0151$ ). The daily intake of seeds and nuts did not show a significant correlation with the number of gout patients in the adult population (aged $\geq 20$ years) in 2004-2016 ( $\mathrm{r}=0.421$, $\mathrm{p}=0.480$ ), with the number of gout patients in adult men (aged $\geq 20$ years $)$ in 2004-2016 ( $\mathrm{r}=0.366, \mathrm{p}=0.545)$, and with the number of gout patients in adult women (aged $\geq 20$ years) in 2004-2016 ( $\mathrm{r}=-0.434, \mathrm{p}=0.465)$.

Almonds, hazelnuts, pecan nuts, and pistachio nuts contain polyphenols that suppress uric acid (UA) production by inhibition of xanthine oxidase activity [66]. In an epidemiological study, increased intake of peanuts was associated with decreased serum uric acid (SUA) concentration [13]. It seems important to actively choose above nuts in order to maintain SUA concentration at normal levels in healthy people. In a cross-sectional study, increased intake of walnuts or pine nuts was inversely associated with decreased hyperuricemia risk [74].

High intake of nuts was associated with reduced risk for kidney disease [45]. Consumption of tree nuts was associated with a reduction in cardiovascular disease risk [71]. The guidelines have encouraged intake of nuts and seeds for hypertension patients [73] or diabetes mellitus patients [53] and intake of $30 \mathrm{~g}$ unsalted nuts per day for cardiovascular disease (CVD) prevention [52].

Intake of seeds and nuts of Japanese people in 2016 was 2.5 g. Saag and Choi have recommended that intake of nuts and legumes should be 1 to 3 servings [75]. The Ministry of Health, Labour and Welfare in Japan has recommended an intake of legumes of $100 \mathrm{~g}$ or more per day [7]. Schlesinger has recommended intake of nuts 1-3 times per day (13-15 g per 
once) [76]. It is considered that intake of seeds and nuts of Japanese people was too low. Higher intake of legumes and nuts was associated with decreased gout risk [15]. Considering the result from the balance of the caloric ratio of protein, fat and carbohydrate in Japanese people in 2016 (protein: $14.8 \%$, fat: $27.4 \%$, and carbohydrates: $57.8 \%$ ) and the daily dietary fiber, vitamin $A$, vitamin $B_{1}$, vitamin $B_{2}$, vitamin $\mathrm{B}_{6}$, pantothenic acid, folate, potassium, magnesium, phosphorus, zinc intake, it seems that increase in daily intake of seeds and nuts is needed for the prevention of gout.

\subsection{Fruit and Vegetables}

Fruit and vegetables are a rich source of carbohydrates, dietary fiber, vitamin $\mathrm{A}$ ( $\beta$-carotene), vitamin $\mathrm{C}$, vitamin $\mathrm{E}$, potassium, and magnesium $[9,10,77]$. Other important constituents are phytochemicals such as antioxidants, is flavones, flavonoids, and polyphenols [77].

\subsubsection{Fruit}

The daily total fruit intake of Japanese people in 2016 was higher compared to that in 1957, 1961, and 1965 and was lower compared to that in 1971, 1975, 1980, 1986, 1989, 1992, 1995, 1998, 2001, 2004, 2007, 2010, and 2013 (1957: 29.5 g/day; 1961: 46.4 g/day; 1965: 58.8 g/day; 1971: 110.5 g/day; 1975: $193.5 \mathrm{~g} /$ day; 1980: $155.2 \mathrm{~g} /$ day; 1986: $137.0 \mathrm{~g} /$ day; 1989: 127.9 g/day; 1992: $126.1 \mathrm{~g} /$ day; 1995: $133.0 \mathrm{~g} /$ day; 1998: $115.5 \mathrm{~g} /$ day; 2001: $132.0 \mathrm{~g} /$ day; 2004: $119.2 \mathrm{~g} /$ day; 2007: $111.6 \mathrm{~g} /$ day; 2010: $101.7 \mathrm{~g} /$ day; 2013: $111.9 \mathrm{~g} /$ day; 2016: $98.9 \mathrm{~g} /$ day).

The daily intake of total fruit, total fruit plus jam, citruses, apples, strawberries, and other fruit was negatively correlated with the number of gout patients in 1986-2016, respectively (total fruit: $\mathrm{r}=-0.855, \mathrm{p}=0.000805$; total fruit plus jam: $\mathrm{r}=$ $-0.854, \mathrm{p}=0.000811$; citruses: $\mathrm{r}=-0.921, \mathrm{p}=0.0000570$; apples: $\mathrm{r}=-0.918, \mathrm{p}=0.0000674$; strawberries: $\mathrm{r}=-0.902, \mathrm{p}=0.000147$; other fruit: $r=-0.706, p=0.0151)$. The daily total fruit intake did not show a significant correlation with the number of gout patients in the adult population (aged $\geq 20$ years) in 2004-2016 $(\mathrm{r}=-0.533, \mathrm{p}=0.355)$, and with the number of gout patients in adult men (aged $\geq 20$ years) in 2004-2016 ( $\mathrm{r}=-0.458$, $\mathrm{p}=0.438$ ). The daily total fruit intake was positively correlated with the number of gout patients in adult women (aged $\geq 20$ years $)$ in 2004-2016 ( $\mathrm{r}=0.971, \mathrm{p}=0.00603)$. This result suggests that the correlation of daily fruit intake with the number of gout patients varies with gender and is stronger in adult women than in adult men.

Blackberries, black currants, black elderberries, European cranberries, apricots, grapes, fox grapes, nectarines, peaches, plums, red raspberries, sour cherries, strawberries, sweet cherries, quinces, loquats, apples, pears, and custard apples contain polyphenols that suppress uric acid (UA) production by inhibition of xanthine oxidase activity [66]. It seems important to actively choose above fruit in order to maintain serum uric acid (SUA) concentration at normal levels in healthy people.

In clinical trials, cherries and cherry products [78-81], Terminalia chebula or Terminalia bellerica [82] decreased
SUA concentrations. In epidemiological studies, increased intake of fruit [14, 23, 25] and noncitrus fruit [13] was associated with decreased SUA concentrations. Eating $280 \mathrm{~g}$ of cherries in healthy volunteers reduced plasma UA (PUA) concentration by $0.031 \mathrm{mmol} / \mathrm{L}$ over a 5 -h period [79].

Clinical case reports of three patients with gout showed that consumption of $227 \mathrm{~g}$ of cherry products daily for 3 days to 3 months reduced PUA to normal levels and alleviated attacks of gouty arthritis [78]. Eating cherries may reduce the frequency of acute gout flares [83]. A retrospective study demonstrated that regular use of cherry juice concentrate led to a significant reduction in flares over a minimum period of 4 months [84].

There is a relatively small amount of fructose in an individual fruit and the presence of other nutrients in the fruit (e.g., fiber, vitamin $\mathrm{C}$, and many important secondary metabolites) may slow fructose absorption or partially block the fructose metabolic effect of UA formation and inhibit superoxide generation [85].

The guidelines recommended the following for fruit intake: (1) encourage intake of cherries for patients with gout [42]; (2) increased fruit intake in adults with chronic kidney disease (CKD) (CKD stages 1-4) [86]; (3) encourage intake of avocados for patients with hypertension [73]; (4) fruit intake in obese or diabetic patients who need to limit their energy intake should be limited to about $80 \mathrm{kcal} /$ day [65]; and (5) daily fruit intake $(\geq 200 \mathrm{~g} /$ day: $2-3$ servings $)$ for cardiovascular disease (CVD) prevention [52].

The US Department of Agriculture recommended 2 to 4 servings per day for fruit in the Dietary Guidelines for Americans [87]. The Dietary guidelines for Japanese (the Japanese food guide spinning top) has recommended that daily consumption of fruit must be 2-3 servings (approximately 200-300 g), depending on an individual's caloric intake [20]. The daily fruit intake of Japanese people in 2016 was $98.9 \mathrm{~g}$. The daily intake of fruit of Japanese people in 2016 was less than the daily recommended fruit intake by the US Department of Agriculture [87] and the Ministry of Health, Labour and Welfare in Japan [7]. Higher intake of fruit [25], less sugary fruit [15], cherries [83] was associated with decreased gout risk. Considering the daily dietary fiber, vitamin $\mathrm{A}$, vitamin $\mathrm{B}_{6}$, vitamin $\mathrm{C}$, folate, potassium, magnesium, phosphorus, iron intake, it seems better to increase the daily intake of fruit (especially less sugary fruit and cherries) for the prevention of gout.

\subsubsection{Vegetables}

The daily intake of vegetables plus mushrooms of Japanese people in 2016 was higher compared to that in 1957, 1961, 1965, 1971, 1975, 1980, and 1986 (1957: $197.5 \mathrm{~g} /$ day; 1961: 198.9 g/day; 1965: 219.4 g/day; 1971: 268.6 g/day; 1975: 246.7 g/day; 1980: $281.4 \mathrm{~g} /$ day; 1986: $260.1 \mathrm{~g} /$ day; 2016: $281.9 \mathrm{~g} /$ day). The daily intake of vegetables of Japanese people in 2016 was higher compared to that in 1986, 1989, 1992, 1998, and 2004 and was lower compared to that in 1995, 2001, 2007, 2010, and 2013 (1986: $260.1 \mathrm{~g} /$ day; 1989: $253.5 \mathrm{~g} /$ day; 1992: $257.9 \mathrm{~g} /$ day; 1995: 278.4 g/day; 1998: 260.6 g/day; 2001: 279.5 g/day; 2004 : 
253.8 g/day; 2007: $276.8 \mathrm{~g}$ /day; 2010: 267.9 g/day; 2013: 271.3 g/day; 2016: $265.9 \mathrm{~g} /$ day).

The daily intake of total vegetables, green and yellow vegetables, carrots, onions, cabbages, tomatoes, radishes, cucumbers, Chinese cabbages, spinach, and pickles of Japanese people in 2016 was $253.7 \mathrm{~g}, 84.4 \mathrm{~g}, 19.8 \mathrm{~g}, 34.4 \mathrm{~g}$, $29.0 \mathrm{~g}, 17.3 \mathrm{~g}, 25.8 \mathrm{~g}, 9.0 \mathrm{~g}, 15.6 \mathrm{~g}, 8.3 \mathrm{~g}$, and $8.7 \mathrm{~g}$, respectively. The daily intake of total vegetables, green and yellow vegetables, carrots, green peppers, and other vegetables did not show a significant correlation with the number of gout patients in 1986-2016, respectively (total vegetables: $\mathrm{r}=-0.0687, \mathrm{p}=0.841$; green and yellow vegetables: $\mathrm{r}=0.356, \mathrm{p}=0.283$; carrots: $\mathrm{r}=0.507, \mathrm{p}=0.112$; green peppers: $\mathrm{r}=0.460, \mathrm{p}=0.155$; other vegetables: $\mathrm{r}=0.107, \mathrm{p}=0.753$ ). The daily intake of onions, cabbages, and tomatoes was positively correlated with the number of gout patients in 1986-2016, respectively (onions: $\mathrm{r}=0.950, \mathrm{p}=0.00000757$; cabbages: $\mathrm{r}=0.737, \mathrm{p}=0.00968$; tomatoes: $\mathrm{r}=0.695, \mathrm{p}=0.0175$ ). Whereas the daily intake of radishes, cucumbers, Chinese cabbages, spinach, and pickles was negatively correlated with the number of gout patients in 1986-2016, respectively (radishes: $\mathrm{r}=-0.857, \mathrm{p}=0.000739$; cucumbers: $\mathrm{r}=-0.828, \mathrm{p}=0.00166$; Chinese cabbages: $r=-0.640, p=0.0340$; spinach: $r=-0.748$, $\mathrm{p}=0.00813$; pickles: $\mathrm{r}=-0.971, \mathrm{p}=0.000000702$ ). The daily intake of total vegetables did not show a significant correlation with the number of gout patients in the adult population (aged $\geq 20$ years) in 2004-2016 ( $\mathrm{r}=-0.0320$, $\mathrm{p}=0.959$ ), with the number of gout patients in adult men (aged $\geq 20$ years $)$ in 2004-2016 ( $\mathrm{r}=0.0464, \mathrm{p}=0.941)$, and with the number of gout patients in adult women (aged $\geq 20$ years) in 2004-2016 $(\mathrm{r}=-0.377, \mathrm{p}=0.531)$.

The daily intake of tomatoes of Japanese people in 2016 was $17.3 \mathrm{~g}$. In epidemiological studies, increased intake of tomatoes and tomato juice was associated with increased serum uric acid (SUA) concentrations [13,88]. A prospective clinical trial in 35 young women showed that raw ripe tomato intake $(\sim 90 \mathrm{~g})$ before lunch for 4 weeks has been significantly associated with a decrease in SUA concentration with $0.16 \mathrm{mg} / \mathrm{dL}$ [89]. In a crossover study, consumption of tomato sauce $(150 \mathrm{~g})$ increased plasma UA (PUA) concentration by $46 \mu \mathrm{mol} / \mathrm{L}$ at $48 \mathrm{~h}$ compared with the baseline (before consuming tomato sauce) [90]. The intervention study showed no significant difference in PUA or SUA concentration after consumption of tomato sauce [91], tomato extract [92] or tomato juice [93]. These differences in outcomes may be attributed to the amount of tomato intake per week and the method of tomato preparation, which can influence the contents of chemicals that affect SUA levels. The daily intake of tomatoes was positively correlated with the number of gout patients in 1986-2016 ( $\mathrm{r}=0.695, \mathrm{p}=0.0175)$.

The daily intake of carrots of Japanese people in 2016 was $19.8 \mathrm{~g}$. In an epidemiological study, increased intake of carrots was associated with decreased SUA concentrations [18]. The daily intake of carrots did not show a significant correlation with the number of gout patients in 1986-2016 ( $\mathrm{r}=0.507$, $\mathrm{p}=0.112$ ). Conscious intake of carrots seems to be important for the prevention of gout.

Spinach intake (294 g) increased SUA concentrations in elderly women [94]. The daily intake of spinach was negatively correlated with the number of gout patients in 1986-2016 $(\mathrm{r}=-0.748, \mathrm{p}=0.00813)$. The daily intake of spinach of Japanese people in 2016 was $8.3 \mathrm{~g}$. It seems better to increase the daily spinach intake slightly but must not take in excessive.

In an epidemiological study, increased intake of bamboo shoots was associated with increased SUA concentrations [18]. Though bamboo shoots are purine-rich foods (30.8-63.3 $\mathrm{mg} / 100 \mathrm{~g}$ ) [95], they contain high in dietary fiber, protein, and potassium (dietary fiber: $3.3 \mathrm{~g} / 100 \mathrm{~g}$; protein: $3.5 \mathrm{~g} / 100 \mathrm{~g}$; potassium: $470 \mathrm{mg} / 100 \mathrm{~g}$ ) [9]. The Ministry of Health, Labour and Welfare in Japan has not investigated the daily intake of bamboo shoots.

Intake of purine-rich vegetables (peas, beans, lentils, cauliflowers, and spinach) was not associated with PUA concentrations in a population-based case-control study conducted in Scotland (1999-2006) [24]. In epidemiological studies, there was no association between intake of purine-rich vegetables (peas, beans, lentils, spinach, mushrooms, and cauliflowers) and hyperuricemia risk [28] or gout risk [35, 36]. On the other hand, higher intake of high-purine vegetables was associated with decreased gout risk [28].

Black olives, broad bean pods, broccoli, and globe artichokes contain polyphenols that suppress UA production by inhibition of xanthine oxidase activity [66]. It seems important to choose these vegetables in order to maintain SUA concentrations at normal levels in healthy people.

Increased intake of vegetables was associated with decreased hyperuricemia risk [19, 31]. This phenomenon can probably explain that increased intake of vegetable protein [36] and dietary fiber [16] protect against risk of gout through decreased hyperuricemia risk.

Garlic (Allium sativum) (raw garlic, dried garlic, garlic oil or a prepared commercial product) has been widely used for gout and rheumatism [96].

Vegetables contain many nutrients, including folate, antioxidants, and dietary fiber, which contribute to reducing the risk of chronic disease [97]. The guidelines recommended the following for intake of vegetables: (1) encourage intake of vegetables for patients with gout $[42,43]$; (2) increase intake of vegetables in adults with chronic kidney disease (CKD) (CKD stages 1-4) [86]; (3) encourage intake of rich in vegetables for patients with urolithiasis [98]; (4) increase intake of vegetables high in nitrates known to reduce blood pressure, such as leafy vegetables and beetroots for patients with hypertension [73]; (5) active intake of vegetables and fruit, except for patients with renal impairment who need to limit their potassium intake [65]; and (6) daily intake of vegetables ( $\geq 200 \mathrm{~g} /$ day: 2-3 servings) for cardiovascular disease (CVD) prevention [52].

The US Department of Agriculture recommended 3 to 5 servings per day for vegetables in the Dietary Guidelines for Americans [87]. The Ministry of Health, Labour and Welfare in Japan has recommended that daily consumption of vegetables must be $350 \mathrm{~g}$ or more (green-yellow vegetables, $120 \mathrm{~g}$ or more) [7]. The daily intake of vegetables of Japanese 
people in 2016 was less than the daily recommended vegetables intake by the US Department of Agriculture [87] and the Ministry of Health, Labour and Welfare in Japan [7]. Considering the daily dietary fiber, vitamin $\mathrm{A}$, vitamin $\mathrm{B}_{1}$, vitamin $\mathrm{B}_{2}$, vitamin $\mathrm{B}_{6}$, vitamin $\mathrm{C}$, pantothenic acid, folate, calcium, potassium, magnesium, phosphorus, iron intake, it seems better to increase the daily intake of vegetables for the prevention of gout.

\subsubsection{Fruit and Vegetables}

In epidemiological studies, increased intake of fruit and vegetables was associated with decreased serum uric acid (SUA) concentrations [18], hyperuricemia risk [32], and gout risk $[16,48]$.

The World Health Organization [99] has recommended increasing fruit and vegetables (to 400-500 g daily) for the prevention of cardiovascular disease (CVD) in healthy adults. Australian government has proposed " 2 fruit \& 5 vegetables" [100]. The dietary guideline in the U.S. call for 5 to 13 servings of fruit and vegetables a day, depending on an individual's caloric intake [101]. The daily intake of total fruit and vegetables of Japanese people in 2016 was $364.8 \mathrm{~g}$. The daily intake of total fruit and vegetables of Japanese people in 2016 was less than the daily recommended fruit intake by the US Department of Agriculture [101]. Increase in daily intake of fruit and vegetables of Japanese people seems to be essential for the prevention of gout through reduced SUA concentrations and decreased hyperuricemia risk.

\section{Relationship Between the Number of Gout Patients and Intake of Seasonings and Condiments or Oils and Fats in Japanese People}

\subsection{Seasonings and Condiments}

The daily intake of soy sauce of Japanese people in 2016 was lower compared to that in 1986, 1989, 1992, 1995, 1998, 2001, 2004, 2010, and 2013 and was higher compared to that in 2007 (1986: $21.3 \mathrm{~g} /$ day; 1989: $21.2 \mathrm{~g} /$ day; 1992: $21.0 \mathrm{~g} /$ day; 1995: 21.6 g/day; 1998: 20.5 g/day; 2001: 18.4 g/day; 2004: 16.6 g/day; 2007: 11.2 g/day; 2010: 14.9 g/day; 2013: $13.1 \mathrm{~g} /$ day; 2016: $12.3 \mathrm{~g} /$ day). The daily sauce intake of Japanese in 2016 was lower compared to that in 1986, 1989, 1992, 1995, 1998, 2001, 2004, 2007, and 2010 and was higher compared to that in 2013 (1986: 3.8 g/day; 1989: 4.5 g/day; 1992: 4.4 g/day; 1995: $4.6 \mathrm{~g} /$ day; 1998: $4.3 \mathrm{~g} /$ day; 2001: $2.5 \mathrm{~g} / \mathrm{day} ; 2004: 2.1 \mathrm{~g} /$ day; 2007: $2.0 \mathrm{~g} /$ day; 2010: $2.0 \mathrm{~g} /$ day; 2013: $1.7 \mathrm{~g} /$ day; 2016: 1.8 $\mathrm{g} /$ day). The daily mayonnaise intake of Japanese in 2016 was lower compared to that in 1986, 1989, 1992, 1995, 1998, 2001, 2004, 2007, and 2010 and was higher compared to that in 2013 (1986: 4.2 g/day; 1989: $5.1 \mathrm{~g} /$ day; 1992: $5.0 \mathrm{~g} /$ day; 1995: 5.1 g/day; 1998: 4.8 g/day; 2001: 3.4 g/day; 2004: 3.3 g/day; 2007: $3.4 \mathrm{~g} /$ day; 2010: $3.0 \mathrm{~g} /$ day; 2013: $2.8 \mathrm{~g} /$ day; 2016: $2.9 \mathrm{~g} /$ day).

The daily intake of soy sauce, sauce, mayonnaise was negatively correlated with the number of gout patients in
1986-2016, respectively (soy sauce: $\mathrm{r}=-0.905, \mathrm{p}=0.000128$; sauce: $\mathrm{r}=-0.917, \mathrm{p}=0.0000725$; mayonnaise: $\mathrm{r}=-0.898$, $\mathrm{p}=0.000175)$. The daily intake of seasonings and spices did not show a significant correlation with the number of gout patients in the adult population (aged $\geq 20$ years) in 2004-2016 $(\mathrm{r}=-0.404, \mathrm{p}=0.500)$, with the number of gout patients in adult men (aged $\geq 20$ years) in 2004-2016 ( $\mathrm{r}=-0.507, \mathrm{p}=0.383$ ), and with the number of gout patients in adult women (aged $\geq 20$ years $)$ in 2004-2016 ( $\mathrm{r}=0.414, \mathrm{p}=0.489)$.

Soy paste (miso) contains polyphenols that suppress uric acid (UA) production by inhibition of xanthine oxidase activity [66]. However, the amount of salt contained in the soy paste (miso), soy sauce, and sauce was $9.7 \mathrm{~g} / 100 \mathrm{~g}, 12.8$ $\mathrm{g} / 100 \mathrm{~g}$ and 5.6-8.5 g/100g, respectively [9]. It seems necessary to decrease the daily intake of soy paste (miso), soy sauce, and sauce in order to reduce the daily salt intake.

The amount of fat contained in the mayonnaise is 9.04 $\mathrm{g} / 100 \mathrm{~g}$ [9]. Considering the mean ratio of energy intake from fat in total energy intake (Fat/Energy), the daily mayonnaise intake seems to be appropriate or it seems better to decrease.

Spices (capers, caraways, cloves, cumin) contain polyphenols that suppress UA production by inhibition of xanthine oxidase activity [66]. It seems important to cook dishes using above spices in order to maintain serum uric acid (SUA) concentrations at normal levels in healthy people.

The 2012 American College of Rheumatology (ACR) Guidelines for Management of Gout have recommended limiting intake of sauces and gravies in all gout patients [43] The British Society for Rheumatology Guidelines for the Management of Gout has recommended avoiding yeast extract intake for patients with gout [42].

\subsection{Oils and Fats}

The daily intake of oils and fats of Japanese people in 2016 was higher compared to that in 1957, 1961, 1965, 2004, 2007, 2010, and 2013 was lower compared to that in 1971, 1975, 1980, 1986, 1989, 1992, 1995, 1998, and 2001 (1957: 4.6 g/day; 1961: 6.7 g/day; 1965: 10.2 g/day; 1971: 17.3 g/day; 1975: 15.8 g/day; 1980: 16.9 g/day; 1986: 16.8 g/day; 1989: 18.7 g/day; 1992: 18.0 g/day; 1995: 17.3 g/day; 1998: 16.0 g/day; 2001: $11.3 \mathrm{~g} /$ day; 2004: $10.5 \mathrm{~g} /$ day; 2007: $10.2 \mathrm{~g} /$ day; 2010: $10.1 \mathrm{~g} /$ day; 2013: $10.3 \mathrm{~g} /$ day; 2016: $10.9 \mathrm{~g} /$ day).

The daily intake of oils and fats, margarine, vegetable oils and fats, animal oils and fats was negatively correlated with the number of gout patients in 1986-2016, respectively (oils and fats: $\mathrm{r}=-0.928, \mathrm{p}=0.0000383$; margarine: $\mathrm{r}=-0.850$, $\mathrm{p}=0.000926$; vegetable oils and fats: $\mathrm{r}=-0.856, \mathrm{p}=0.000780$; animal oils and fats: $r=-0.643, p=0.0327$ ). The daily butter intake did not show a significant correlation with the number of gout patients in 1986-2016 $(\mathrm{r}=-0.0445, \mathrm{p}=0.897)$. However, compared to the ideal balance of the caloric ratio of protein, fat, and carbohydrate of Japanese people (protein: 15\%, fat: $25 \%$, and carbohydrates: $60 \%$ ) [102], the balance in Japanese people in 2016 was weighted toward fat (protein: $14.8 \%$, fat: $27.4 \%$, and carbohydrates: $57.8 \%$ ). The daily intake of oils and fats seems better to decrease until the mean ratio of energy intake from fat in total energy intake (Fat/Energy) becomes 25\%. 


\section{Relationship Between the Number of Gout Patients and Confectionery Intake in Japanese People}

The daily intake of confectioneries of Japanese people in 2016 was higher compared to that in 1961, 1980, 1986, 1989, $1992,1998,2004$, and 2010 and was lower compared to that in $1965,1971,1975,1995,2001$, and 2013 and was the same as that in 2007 (1961: $22.4 \mathrm{~g} /$ day; 1965: $31.6 \mathrm{~g} /$ day; 1971: 37.1 g/day; 1975: 29.0 g/day; 1980: 25.0 g/day; 1986: 22.9 g/day; 1989: 22.0 g/day; 1992: 20.9 g/day; 1995: 26.8 g/day; 1998: $24.3 \mathrm{~g} /$ day; 2001: $26.7 \mathrm{~g} /$ day; 2004: $25.6 \mathrm{~g} /$ day; 2007: 26.3 g/day; 2010: $25.1 \mathrm{~g} /$ day; 2013: $26.7 \mathrm{~g} /$ day; 2016: $26.3 \mathrm{~g} /$ day). The daily jam intake of Japanese people in 2016 was higher compared to that in 1986, 1989, 1992, 1995, 1998, 2001, 2004, 2007, and 2010 and was the same as that in 2013 (1986: 0.6 g/day; 1989: $1.1 \mathrm{~g} /$ day; 1992: $1.1 \mathrm{~g} /$ day; 1995: $1.2 \mathrm{~g} /$ day; 1998: $1.1 \mathrm{~g} /$ day; 2001: $0.9 \mathrm{~g} /$ day; 2004: $1.1 \mathrm{~g} /$ day; 2007: $1.2 \mathrm{~g} /$ day; 2010: 1.2 g/day; 2013: $1.3 \mathrm{~g} /$ day; 2016: $1.3 \mathrm{~g} /$ day).

The daily intake of confectioneries and jam was positively correlated with the number of gout patients in 1986-2016, respectively (confectioneries: $\mathrm{r}=0.711$, $\mathrm{p}=0.0142$; jam: $\mathrm{r}=0.617, \mathrm{p}=0.0433$ ). It seems that decrease in daily intake of confectioneries and jam in Japanese people is essential for the prevention of gout. The daily intake of confectioneries was positively correlated with the number of gout patients in the adult population (aged $\geq 20$ years $)$ in 2004-2016 $(\mathrm{r}=0.897, \mathrm{p}=0.0392)$. The daily intake of confectioneries did not show a significant correlation with the number of gout patients in adult men (aged $\geq 20$ years) in 2004-2016 ( $\mathrm{r}=0.875, \mathrm{p}=0.0519)$, and with the number of gout patients in adult women (aged $\geq 20$ years) in 2004-2016 $(\mathrm{r}=0.0117, \mathrm{p}=0.985)$. This result suggests that the correlation of daily confectioneries intake with the number of gout patients tends to be stronger in adult men than in adult women.

Chocolates and cocoa powders contain polyphenols that suppress uric acid (UA) production by inhibition of xanthine oxidase activity [66]. The consumption of chocolate powders and dark chocolates decreased UA crystallization through the increase in the amount of urinary theobromine [103]. Recent research indicated that theobromine, which is a dimethylxanthine that is abundant in cocoas and chocolates, can inhibit UA crystallization, suggesting it may be useful for the prevention of UA urolithiasis [104].

The 2012 American College of Rheumatology (ACR) Guidelines for Management of Gout [43] have recommended limiting intake of desserts in all gout patients.

\section{Relationship Between the Number of Gout Patients and Beverage Consumption in Japanese People}

\subsection{Beverages}

The daily beverage consumption of Japanese people in
2016 was lower compared to that in 2004, 2007, and 2013 and was higher compared to that in 2010 (2004: $698.6 \mathrm{~g} / \mathrm{day} ; 2007$ : $709.2 \mathrm{~g} /$ day; 2010: $663.5 \mathrm{~g} / \mathrm{day} ; 2013: 668.5 \mathrm{~g} /$ day; 2016: $664.9 \mathrm{~g} /$ day).

The daily beverage consumption did not show a significant correlation with the number of gout patients in the adult population (aged $\geq 20$ years) in 2004-2016 ( $\mathrm{r}=-0.849$, $\mathrm{p}=0.0689$ ), with the number of gout patients in adult men (aged $\geq 20$ years) in 2004-2016 $(\mathrm{r}=-0.868, \mathrm{p}=0.0563)$, and with the number of gout patients in adult women (aged $\geq 20$ years $)$ in 2004-2016 $(\mathrm{r}=0.652, \mathrm{p}=0.233)$. This result suggests that the correlation of daily beverage consumption with the number of gout patients tends to vary with gender.

\subsection{Sugar-sweetened Beverages}

Consumption of sugar-sweetened beverages, a major source of fructose, has risen sharply in recent decades all over the world [105].

In epidemiological studies, increased intake of soft drinks [13] was associated with increased serum uric acid (SUA) concentrations. In epidemiological studies, increased intake of sugar-sweetened beverages was associated with increased SUA concentrations [18, 22-24, 106-108], hyperuricemia risk [29, 106, 109-111], and gout risk [15, 22, 35, 107, 111, 112]. Consumption of sugary beverages is low, because limiting intake of sugary beverages would reduce SUA levels [38]. Higher intake of high fructose corn syrup sources in products such as soft drinks can result in new onset of acute gout attacks [113]. These results suggest that a decrease in daily intake of sugar-sweetened beverages and soft drinks in Japanese people is essential for the prevention of gout.

The guidelines recommended the following for sugar-sweetened beverage intake: (1) limit intake of high fructose corn syrup-sweetened soft drinks and energy drinks, sweetened beverages, including serving of naturally sweet fruit juices and avoidance of high fructose corn syrup-sweetened sodas, other beverages, or foods for patients with gout [43]; (2) avoidance of intake of sugar-sweetened drinks for patients with gout [41]; (3) avoidance of intake of sugar-sweetened beverages including fruit juices and the minimize the consumption of foods with added sugar that have the capacity to displace healthier, more nutrient-dense food choices for subjects with diabetes mellitus and those at risk [53]; (4) encourage to decrease intake both sweetened and nonnutritive-sweetened beverages for patients with diabetes mellitus [53]; and (5) discourage sugar-sweetened soft drink intake for cardiovascular disease (CVD) prevention [52].

\subsection{Coffee and Tea}

1. Coffee

In epidemiological studies, increased intake of coffee was associated with decreased serum uric acid (SUA) concentrations [18, 114-116], hyperuricemia risk [26, 28, 35, $114,115]$, and gout risk [15, 28, 34, 35, 117-121]. Coffee 
intake may prevent gout through a reduction of SUA concentrations and a decrease in hyperuricemia risk.

\section{Tea}

Intake of green tea [122] and black tea [123] decreased serum uric acid (SUA) concentrations. In epidemiological studies, increased intake of green tea was associated with increased SUA concentrations [124] but increased intake of tea drunk by Chinese adults was associated with decreased hyperuricemia risk [48, 125].

3. Coffee and Tea

Coffee, green tea, and black tea contain caffeine (1,3,7-trimethyl xanthine). The amounts of caffeine contained in the leachate of coffee, green tea (gyokuro), green tea (sencha), and black tea were $60 \mathrm{mg} / 100 \mathrm{~mL}, 160 \mathrm{mg} / 100 \mathrm{~mL}$, $20 \mathrm{mg} / 100 \mathrm{~mL}$, and $30 \mathrm{mg} / 100 \mathrm{~mL}$, respectively. In epidemiological studies, increased caffeine intake was associated with decreased serum uric acid (SUA) concentrations $[15,61,126,127]$. Proposed mechanisms of higher coffee and tea intake associated with lower SUA levels and reduced hyperuricemia risk are reviewed in detail by Koguchi [4]. Soluble dietary fiber suppresses the digestion and/or absorption of dietary purines in rats [4]. Caffeine may inhibit xanthine oxidase activity [128] and enhance renal uric acid (UA) excretion [129]. Antioxidants, such as the phenol chlorogenic acid in coffee, the catechin in green tea, and the theaflavin in black tea may reduce SUA concentrations by inhibition of xanthine oxidase activity [130]. European Food Safety Authority (EFSA) [131] has recommended that the maximum daily intake of caffeine in healthy adults except pregnant women is $400 \mathrm{mg}$. It is imperative to drink coffee and/or tea, taking into account the daily caffeine intake.

Since higher intake of coffee and tea decrease serum uric acid (SUA) concentrations and hyperuricemia risk, it seems that coffee and tea play an important role for the prevention of gout. The daily consumption of coffee and green tea in Japanese people in 2016 was 1.58 cups and 3.1 cups, respectively [132]. Poole et al. [120] have stated that the daily coffee consumption is three to four cups.

The guidelines recommended the following for intake of coffee and tea: (1) encourage intake of coffee for patients with gout [42]; (2) moderate consumption of coffee, green tea, and black tea for patients with hypertension [73]; and (3) encourage intake of karkadé (hibiscus) tea, pomegranate juice, beetroot juice and cocoa beverage for patients with hypertension [73].

\subsection{Alcoholic Beverages}

The daily consumption of alcoholic beverages of Japanese people in 2016 was higher compared to that in 1986, 1989, 1992, 1995, 1998, 2001, 2004, and 2010 and was lower compared to that in 2007 and 2013 (1986: $54.4 \mathrm{~g} /$ day; 1989: $56.8 \mathrm{~g} /$ day; 1992: 68.9 g/day; 1995: $87.1 \mathrm{~g} /$ day; 1998: 95.1 g/day; 2001: 93.5 g/day; 2004: 98.5 g/day; 2007: 99.7 g/day; 2010: $92.1 \mathrm{~g} /$ day; 2013: $101.0 \mathrm{~g} /$ day; 2016: $99.1 \mathrm{~g} / \mathrm{day})$. The daily consumption of beer of Japanese in 2016 was higher compared to that in 1986, 1989, 1992, 1995, 2001, 2004, 2007, and 2010 and was lower compared to that in 1998 and 2013
(1986: $28.9 \mathrm{~g} /$ day; 1989: $36.3 \mathrm{~g} /$ day; 1992: $45.1 \mathrm{~g} / \mathrm{day}$; 1995 : 60.6 g/day; 1998: 68.7 g/day; 2001: 59.2 g/day; 2004: 61.1 g/day; 2007: 61.5 g/day; 2010: 54.1 g/day; 2013: 63.3 g/day; 2016: $62.0 \mathrm{~g} /$ day). The daily consumption of other liquors (e.g., foreign liquors) of Japanese in 2016 was higher compared to that in 1986, 1989, 1992, 1995, 1998, 2001, 2004, 2007, 2010, and 2013 (1986: 6.0 g/day; 1989: 5.6 g/day; 1992: $6.8 \mathrm{~g} /$ day; 1995: $8.4 \mathrm{~g} /$ day; 1998: $10.3 \mathrm{~g} /$ day; 2001: $20.5 \mathrm{~g} /$ day; 2004: 26.2 g/day; 2007: 27.6 g/day; 2010: 26.7 g/day; 2013: $27.5 \mathrm{~g} /$ day; 2016: $28.6 \mathrm{~g}$ /day).

Alcoholic beverage consumption increased plasma uric acid (PUA) or serum uric acid (SUA) concentrations [133-135]. In epidemiological studies, increased consumption of alcoholic beverages was associated with increased SUA concentrations $[13,14,25,136,137]$, hyperuricemia risk [19, 46], and gout risk [35]. The daily consumption of alcoholic beverages was positively correlated with the number of gout patients in 1986-2016 $(\mathrm{r}=0.861, \mathrm{p}=0.000654)$. This result suggests that a decrease in daily consumption of alcoholic beverages in Japanese people is essential for the prevention of gout.

The daily consumption of alcoholic beverages, beer, other liquors (e.g., foreign liquors) was positively correlated with the number of gout patients in 1986-2016, respectively (alcoholic beverages: $\mathrm{r}=0.861, \mathrm{p}=0.000654$; beer: $\mathrm{r}=0.695, \mathrm{p}=0.0175$; other liquors (e.g., foreign liquors): $r=0.967, p=0.00000126$ ). Whereas the daily rice wine consumption was negatively correlated with the number of gout patients in 1986-2016 (r= $-0.929, \mathrm{p}=0.0000353)$. This result suggests that the correlation of daily consumption of alcoholic beverages with the number of gout patients tends to vary with the type of alcoholic beverages. A clinical trial showed that the degree of increase in SUA concentration by the same amount of alcohol intake was beer $(15 \%)>$ red wine $(9 \%)>$ spirits $(8 \%)$ [134]. However, Choi et al. [136] found that SUA levels significantly increased with increasing beer or liquor intake, but not with wine intake, and SUA levels decreased with increasing wine intake except for the top category ( $\geq 1$ serving per day). Consumption of wine is moderate, because SUA levels decreased with increasing wine intake $(<1$ servings per day) and moderate wine drinking did not increase SUA levels [136]. Red wine contains polyphenols that suppress uric acid (UA) production by inhibition of xanthine oxidase activity [66]. Moderate red wine or white wine drinking (two 4-oz glasses or more per day: $>236.59 \mathrm{~mL} /$ day) was not associated with an increased gout risk [137]. Wine drinkers had lower SUA levels (in fact, SUA levels comparable to nondrinkers) than did drinkers of other forms of alcoholic beverages [138]. In case of moderate wine consumption, polyphenols in wine confer a protective effect against gout, apart from its antioxidant effect. However, Villegas et al. [46] found that higher consumption of alcoholic drinks (wine, beer, and liquor) was associated with higher prevalence of hyperuricemia in Shanghai men and the prevalence of hyperuricemia was beer $>$ wine (grape and rice) $>$ liquor, in the case of consumption of greater than 3 drinks a day [ethanol amount: beer, $\geq 37.8 \mathrm{~g}$; wine, $\geq 36.9 \mathrm{~g}$; liquor, $\geq 38.7 \mathrm{~g}$ ]. Limit consumption of alcoholic beverages may play an important role in the prevention of gout through a reduction of SUA 
concentrations and a decrease in hyperuricemia risk.

The guidelines recommended the following for alcoholic beverage consumption for cardiovascular disease (CVD) prevention: (1) individuals who take more than 3 units of alcohol per day [3/2 pint of beer/lager ( $5 \%$ alcohol), $300 \mathrm{~mL}$ of wine (10\% alcohol), spirits $25 \mathrm{~mL}$ (40\% alcohol)] should be advised to reduce alcohol consumption [99]; and (2) consumption of alcoholic beverages should be limited to 2 glasses per day ( $20 \mathrm{~g} / \mathrm{d}$ of alcohol) for men and 1 glass per day $(10 \mathrm{~g} / \mathrm{d}$ of alcohol) for women [52].

\section{Conclusion}

In this article, the author showed the relationship between the number of gout patients and food intake in Japanese people and suggested modification of food intake for the prevention of gout in Japanese people referencing the results of clinical research. Modification of food intake for the prevention of gout is suggested as follows: limiting the intake of meat, organ meats high in purine content (e.g., liver kidney), confectioneries (sugary foods including desserts and sweets), and sugar-sweetened beverages; limiting alcohol beverage consumption; limiting or decreasing intake of oils and fats, and seasonings and condiments (soy paste, soy sauce, and sauce); encourage intake of fiber-rich foods (e.g., cereals, whole grains, high-fiber bread), eggs, milk and dairy products (especially low-fat dairy products), legumes, seeds and nuts, fruit, vegetables, and coffee. The above dietary habits for the prevention of gout with proper choices of foods may also play a helpful role in the prevention of gout. It is necessary to recognize what beneficial diet and dietary pattern as potential dietary habits to prevent gout in Japanese people.

\section{Conflict of Interest Statement}

The author declares that there are no conflicts of interest.

\section{Acknowledgements}

The author thanks Prof. Eiko Ota (Kokugakuin University Tochigi Junior College), Ms. Yuko Itabashi, Ms. Tamae Yanagita, Ms. Nao Uzuka, and Ms. Yumi Kuwabara for furnishing references at Kokugakuin University Tochigi Gakuen Library.

\section{References}

[1] Koguchi, T. (2021) Modification of dietary habits for prevention of gout in Japanese people: Gout and the Japanese diet. Am J Health Res, (in press).

[2] Koguchi, T. (2021) Modification of dietary habits for prevention of gout in Japanese people: Gout and macronutrient intake. Am J Health Res, (in press).

[3] Koguchi, T. (2021) Modification of dietary habits for prevention of gout in Japanese people: Gout and micronutrient intake or alcohol consumption. Am J Health Res, (in press).
[4] Koguchi, T. (2018) Essentials of dietary habits for prevention and suppression of hyperuricemia. Curr Top Pharmacol, 22, 77-133.

[5] The Ministry of Health, Labour and Welfare. Household Statistics Office. (2020) Comprehensive Survey of Living Conditions [Internet]. Available from: https://www.mhlw.go.jp/toukei/list/20-21kekka.html.

[6] The Ministry of Health, Labour and Welfare. Health Service Bureau. (2020) National Health and Nutrition Survey Japan, 1946-2017 [Internet]. Available from: https://www.mhlw.go.jp/bunya/kenkou/kenkou_eiyou_chousa. html.

[7] The Ministry of Health, Labour and Welfare, Japan. (2020) Dietary Reference Intakes for Japanese, 2020 [Internet]. Available from: https://www.mhlw.go.jp/file/06-Seisakujouhou-10900000-Ken koukyoku/Overview.pdf.

[8] National Institute of Health and Nutrition [Internet]. Available from:

www.nibiohn.go.jp/eiken/kenkounippon21/eiyouchousa/keine n_henka_time.html.

[9] The Council for Science and Technology, Ministry of Education, Culture, Sports, Science and Technology in Japan. (2020) Standard tables of food composition in Japan -2020(Eighth Revised Edition), Report of the Subdivision Resources [Internet]. Available from: https://www.mext.go.jp/content/20201225-mxt_kagsei-mext_ 01110_011.pdf.

[10] U.S. Department of Health \& Human Services. National Institutes of Health. Office of Dietary Supplements. Dietary Supplement Fact Sheets [Internet]. Available from: Dietary Supplement Fact Sheets (nih.gov).

[11] National Health and Medical Research Council (NHMRC), Australian Government. Australian Guide to Healthy Eating, Eat for Health, Australian Dietary Guidelines, 2013 [Internet]. Available from: https://www.eatforhealth.gov.au/sites/default/files/files/the_gu idelines/n55_australian_dietary_guidelines.pdf.

[12] Loenen, H. M. J. A., Eshuis, H., Löwik, M. R. H., Schouten, E. G., Hulshof, K. F. A. M., Odink, J., \& Kok, F. J. (1990) Serum uric acid correlates in elderly men and women with special reference to body composition and dietary intake (Dutch Nutrition Surveillance System). J Clin Epidemiol, 43, 1297-1303.

[13] Major, T. J., Topless, R. K., Dalbeth, N., \& Merriman, T. R. (2018) Evaluation of the diet wide contribution to serum urate levels: meta-analysis of population based cohorts. BMJ, 363, k3951.

[14] Zykova, S. N., Storhaug, H. M., Toft, I., Chadban, S. J., Jenssen, T. G., \& White, S. L. (2015) Cross-sectional analysis of nutrition and serum uric acid in two Caucasian cohorts: the AusDiab Study and the Tromsø study. Nutr J, 14, 49.

[15] Torralba, K. D., De Jesus, E., \& Rachabattula, S. (2012) The interplay between diet, urate transporters and the risk for gout and hyperuricemia: current and future directions. Int $\mathrm{J}$ Rheum Dis, 15, 499-506.

[16] Lyu, L. C., Hsu, C. Y., Yeh, C. Y., Lee, M. S., Huang, S. H., \& Chen, C. L. (2003) A case-control study of the association of diet and obesity with gout in Taiwan. Am J Clin Nutr, 78, 690-701. 
[17] Hosojima, M., Kaseda, R., Kondo, H., Fujii, M., Kubota, M., Watanabe, R., Tanabe, N., Kadowaki, M., Suzuki, Y., \& Saito, A. (2016) Beneficial effects of rice endosperm protein intake in Japanese men with risk factors for metabolic syndrome: a randomized, crossover clinical trial. BMC Nutr, 2, 25.

[18] Chuang, S. Y., Lee, S. C., Hsieh, Y. T., \& Pan, W. H. (2011) Trends in hyperuricemia and gout prevalence: Nutrition and Health Survey in Taiwan from 1993-1996 to 2005-2008. Asia Pac J Clin Nutr, 20, 301-308.

[19] Yu, K-H., See, L-C., Huang, Y-C., Yang, C-H., \& Sun, J-H. (2008) Dietary factors associated with hyperuricemia in adults. Semin Arthritis Rheum, 37, 243-250.

[20] Ministry of Health, Labour and Welfare and Ministry of Agriculture, Forestry and Fisheries. 2010, Japanese Food Guide Spinning Top, Tokyo. [Internet]. Available from: http://www.maff.go.jp/j/balance_guide/b_sizai/attach/pdf/inde $\mathrm{x}-56 . p d f$.

[21] Brulé, D., Sarwar, G., \& Savoie, L. (1992) Changes in serum and urinary uric acid levels in normal human subjects fed purine-rich foods containing different amounts of adenine and hypoxanthine. J Am Coll Nutr, 11, 353-358.

[22] Xia, Y., Wu, Q., Wang, H., Zhang, S., Jiang, Y., Gong, T., Xu, X., Chang, Q., Niu, K., \& Zhao, Y. (2020) Global, regional and national burden of gout:, 1990-2017: a systematic analysis of the Global Burden of Disease Study. Rheumatology (Oxford), $59,1529-1538$.

[23] Kontogianni, M. D., Chrysohoou, C., Panagiotakos, D. B., Tsetsekou, E., Zeimbekis, A., Pitsavos, C., \& Stefanadis, C. (2012) Adherence to the Mediterranean diet and serum uric acid: the ATTICA study. Scand J Rheumatol, 41, 442-449.

[24] Zgaga, L., Theodoratou, E., Kyle, J., Farrington, S. M., Agakov, F., Tenesa, A., Walker, M., McNeill, G., Wright, A. F., Rudan, I., Dunlop, M. G., \& Campbell, H. (2012) The association of dietary intake of purine-rich vegetables, sugar-sweetened beverages and dairy with plasma urate, in a cross-sectional study. PLoS One, 7, e38123.

[25] Williams, P. T. (2008) Effects of diet, physical activity and performance, and body weight on incident gout in ostensibly healthy, vigorously active men. Am J Clin Nutr, 87, 1480-1487.

[26] Choi, H. K., Liu, S., \& Curhan, G. (2005) Intake of purine-rich foods, protein, and dairy products and relationship to serum levels of uric acid: The Third National Health and Nutrition Examination Survey. Arthritis Rheum, 52, 283-289.

[27] Haldar, S., Rowland, I. R., Barnett, Y. A., Bradbury, I., Robson, P. J., Powell, J., \& Fletcher, J. (2007) Influence of habitual diet on antioxidant status: a study in a population of vegetarians and omnivores. Eur J Clin Nutr, 61, 1011-1022.

[28] Li, R., Yu, K., \& Li, C. (2018) Dietary factors and risk of gout and hyperuricemia: a meta-analysis and systematic review. Asia Pac J Clin Nutr, 27, 1344-1356.

[29] Desideri, G., Puig, J. G., \& Richette, P. (2015) The management of hyperuricemia with urate deposition. Curr Med Res Opin, 31 (Suppl 2), 27-32.

[30] Sigie, T., Imatou, T., Miyazaki, M., \& Une, H. (2005) The effect of alcoholic beverage type on hyperuricemia in Japanese male office workers. J. Epidemiol, 15, 41-47.

[31] Han, Q-X., Zhang, D., Zhao, Y-L., Liu, L., Li, J., Zhang, F.,
Luan, F-X., Liu, D-W., Liu, Z-S., Cai, G-Y., Chen, X-M., \& Zhu, H-Y. (2019) Risk factors for hyperuricemia in Chinese centenarians and near- centenarians. Clinical Interventions in Aging, 14, 2239-2247.

[32] Zhu, J. N., Qi, X. Y., Tan, Y., \& Lyu, X. H. (2016) Dietary factors associated with hyperuricemia and glycolipid metabolism disorder in middle-aged and elderly people. Sichuan. Da Xue Xue Bao Yi Xue Ban, 47, 68-72 (in Chinese).

[33] Guasch-Ferré, M., Bulló, M., Babio, N., Martínez-González, M. A., Estruch, R., Covas, M-I., Wärnberg, J., Arós, F., Lapetra, J., Serra-Majem, L., Basora, J., \& Salas-Salvadó, J. (2013) Mediterranean diet and risk of hyperuricemia in elderly participants at high cardiovascular risk. J Gerontol A Biol Sci Med Sci, 68, 1263-1270.

[34] Doherty, M. (2009) New insights into epidemiology of gout. Rheumatology (Oxford), 48 (suppl 2), ii2-ii8.

[35] Nickolai, B., \& Kiss, C. (2016) Nutritional therapy of gout. Ther Umsch, 73, 153-158.

[36] Choi, H. K., Atkinson, K., Karlson, E. W., Willett, W., \& Curhan, G. (2004) Purine-rich foods, dairy and protein intake, and the risk of gout in men. N Engl J Med, 350, 1093-1103.

[37] Teng, G. G., Pan, A., Yuan, J. M., \& Koh, W. P. (2015) Food sources of protein and risk of incident gout in the Singapore Chinese Health Study. Arthritis Rheumatol, 67, 1933-1942.

[38] Zhu, Y., Pandya, B. J., \& Choi, H. K. (2011) Prevalence of gout and hyperuricemia in the US general population: the National Health and Nutrition Examination Survey 2007-2008. Arthritis Rheum, 63, 3136-3141.

[39] Zhang, Y., Woods, R., Chaisson, C. E., Neogi, T., Niu, J., McAlndon, T. E., \& Hunter, D. (2006) Alcohol consumption as a trigger of recurrent gout attacks. Am J Med, 119, 800, e13-18.

[40] Zhang, Y., Chen, C., Choi, H., Chaisson, C., Hunter, D., Niu, J., $\&$ Neogi, T. (2012) Purine-rich foods intake and recurrent gout attacks. Ann Rheum Dis, 71, 1448-1453.

[41] Richette, P., Doherty, M., Pascual, E., Barskova, V., Becce, F., Castaneda-Sanabria, J. Coyfish, M., Guillo, S., Jansen, T. L., Jansens, H., Lioté, F., Mallen, C., Nuki, G., Perez-Ruiz, F., Pimentao, J., Punzi, L., Pywell, T., So, A., Tausche, A. K., Uhlig, T., Zavada, J., Zhang, W., Tubach, F., \& Bardin, T. (2017) 2016 updated EULAR evidence-based recommendations for the management of gout. Ann Rheum Dis, 76, 29-42.

[42] Jordan, K. M., Cameron, J. S., Snaith, M., Zhang, W., Doherty, M., Seckl, J., Hingorani, A., Jaques, R., Nuki, G., British Society for Rheumatology and British Health Professionals in Rheumatology Standards., \& Guidelines and Audit Working Group (SGAWG) (2007) British Society for Rheumatology and British health professionals in rheumatology guideline for the management of gout. Rheumatology, 46, 1372-1374.

[43] Khanna, D., Fitzgerald, J. D., Khanna, P. P., Bae, S., Singh, M. K., Neogi, T., Pillinger, M. H., Merill, J., Lee, S., Prakash, S., Kaldas, M., Gogia, M., Perez-Ruiz, F., Taylor, W., Lioté, F., Choi, H., Singh, J. A., Dalbeth, N., Kaplan, S., Niyyar, V., Jones, D., Yarows, S. A., Roessler, B., Kerr, G., King, C., Levy, G., Furst, D. E., Edwards, N. L., Mandell, B., Schumacher, H. R., Robbins, M., Wenger, N., \& Terkeltaub, R. (2012) 2012 American College of Rheumatology guidelines for management of gout. Part 1: systematic nonpharmacologic and pharmacologic therapeutic approaches to hyperuricemia. Arthritis Care Research, 64, 1431-1446. 
[44] Kramer, H. (2019) Diet and chronic kidney disease. Adv Nutr, 10, S367-S379.

[45] Rebholz, C. M., Crews, D. C., Grams, M. E., Steffen, L. M., Levey, A. S., Miller, E. R. 3 rd., Appel, L. J., \& Coresh, J. (2016) DASH (Dietary Approaches to Stop Hypertension) diet and risk of subsequent kidney disease. Am J kidney Dis, 68, 853-861.

[46] Villegas, R., Xiang, Y. -B., Elasy, T., Xu, W. H., Cai, H., Cai, Q., Linton, M. F., Fazio, S., Zheng, W., \& Shu, X. -O. (2012) Purine-rich foods, protein intake, and the prevalence of hyperuricemia: the Shanghai Men's Health Study. Nutr Metab Cardiovasc Dis, 22, 409-416.

[47] Xiong, Z., Zhu, C., Qian, X., Zhu, J., Wi, Z., \& Chen, L. (2013) Serum uric acid is associated with dietary and lifestyle factors in elderly women in suburban Guangzhou in Guangdong province of south China. J Nutr Hralth Aging, 17, 30-34.

[48] Yu, J. W., Yang, T. G., Diao, W. H., Cai, X. Q., Li, T., Zhong, H., Hu, D. L., Chen, C. Q., \& Chen, Z. X. (2010) Epidemiological study on hyperuricemia and gout in Foshan areas, Guangdong province. Chin J Epidemiol, 31, 860-862.

[49] Ren, Z., Huang, C., Momma, H., Cui, Y., Sugiyama, S., Niu, K., \& Nagatomi, R. (2016) The consumption of fish cooked by different methods was related to the risk of hyperuricemia in Japanese adults: A 3-year follow-up study. Nutr Metab Cardiovasc Dis, 26, 778-785.

[50] Wang, Y., Yan, S., Li, C., Zhao, S., Lv, J., Wang, F., Meng, D., Han, L., Wang, Y., \& Miao, Z. (2013) Risk factors for gout developed from hyperuricemia in China: a five-year prospective cohort study. Rheumatol Int, 33, 705- 710.

[51] Hisatome, I., Ichida, K., Mineo, I., Ohtahara, A., Ogino, K., Kuwabara, M., Ishizaka, N., Uchida, S., Kurajoh, M., Kohagura, K., Sato, Y., Taniguchi, A., Tsuchihashi, T., Terai, C., Nakamura, T., Hamaguchi, T., Hamada, T., Fujimori, S., Masuda, I., Moriwaki, Y., Yamamoto, T. on behalf of guideline development group. (2018) Japanese Society of Gout and Uric \& Nucleic Acids Guidelines for Management of Hyperuricemia and Gout: 3 rd edition. SHINDAN TO CHIRYO SHA, Inc. pp. 1-169. Tokyo (in Japanese).

[52] Piepoli, M. F., Hoes, A. W., Agewall, S., Albus, C., Brotons, C., Catapano, A. L., Cooney, M-T., Corrà, U., Cosyns, B., Deaton, C., Graham, I., Hall, M. S., Hobbs, F. D. R., Løchen, M-L., Löllgen, H., Marques-Vidal, P., Perk, J., Prescott, E., Redon, J., Richter, D. J., Sattar, N., Smulders, Y., Tiberi, M., van der Worp, H. B., van Dis, I., \& Verschuren, W. H. M.(2016) 2016 European Guidelines on cardiovascular disease prevention in clinical practice. The Sixth Joint Task Force of the European Society of Cardiology and Other Societies on Cardiovascular Disease Prevention in Clinical Practice (constituted by representatives of 10 societies and by invited experts) Developed with the special contribution of the European Association for Cardiovascular Prevention \& Rehabilitation (EACPR). Eur Heart J, 37, 2315-2381.

[53] American Diabetes Association (2019) Lifestyle management: standards of medical care in diabetes-2019. Diabetes Care, 42, S46-S60.

[54] Terkeltaub, R., \& Edwards, N. L. (2013) Gout: Diagnosis and management of gouty arthritis and hyperuricemia. 3rd edition, p. 1-336. Professional Communications, Inc. NY.

[55] Chang, W. C. (2011) Dietary intake and the risk of hyperuricemia, gout and chronic kidney disease in elderly Taiwanese men. Aging Male, 14, 195-202.
[56] Dalbeth, N., Wong, S., Gamble, G. D., Horne, A., Mason, B., Pool, B., Fairbanks, L., McQueen, F. M., Cornish, J., Reid, I. R., \& Palmano, K. (2010) Acute effect of milk on serum urate concentrations: a randomized controlled crossover trial. Ann Rheum Dis, 69. 1677-1682.

[57] Carabin, I. G., Lyon, M. R., Wood, S., Pelletier, X., Donazzolo, Y., \& Burdock, G. A. (2009) Supplementation of the diet with the functional fiber PolyGlycoplex is well tolerated by healthy subjects in a clinical trial. Nutr J, 8, 9 .

[58] Dalbeth, N. and Palmano, K. (2011) Effects of dairy intake on hyperuricemia and gout. Curr Rheumatol Rep, 13, 132-137.

[59] Ghadirian, P., Shatenstein, B., Verdy, M., \& Hamet, P. (1995) The influence of dairy products on plasma uric acid in women. Eur J Epidemiol, 11, 275-281.

[60] Hunter, D. C., Brown, R., Green, T., Thomson, C., Skeaff, M., Williams, S., Todd, J. M., Lister, C. E., McGhie, T., Zhang, J., Martin, H., Rippon, P., Stanley, R., \& Skinner, M. A. (2012) Changes in markers of inflammation, antioxidant capacity and oxidative stress in smokers following consumption of milk, and milk supplemented with fruit and vegetable extracts and vitamin C. Int J Food Sci Nutr, 63, 90-102.

[61] Beydoun, M. A., Fanelli-Kuczmarski, M. T., Canas, J-A., Beydoun, H. A., Evans, M. K., \& Zonderman, A. B. (2018) Dietary factors are associated with serum uric acid trajectory differentially by race among urban adults. Br J Nutr, 120, 935-945.

[62] Moi, J. H., Sriranganathan, M. K., Falzon, I., Edwards, C. J., van der Heijde, D. M., \& Buchbinder, R. (2014) Lifestyle interventions for the treatment of gout: a summary of 2 Cochrane systematic reviews. J Rheumatol, Suppl 92, 26-32.

[63] Garrel, D. R., Verdy, M., PetitClerc, C. Martin, C., Brulé, D., \& Hamet, P. (1991) Milk-and soy-protein ingestion; Acute effect on serum uric acid concentration. Am J Clin Nutr, 53, 665-669.

[64] Dalbeth, N., Ames, R., Gamble, G. D., Horne, A., Wong, S., Kuhn-Sherlock, B., MacGibbon, A., McQueen, F. M., Reid, I. R., \& Palmano, K. (2012) Effects of skim milk powder enriched with glycomacropeptide and G600 milk fat extract on frequency of gout flares: a proof-of-concept randomised controlled trial. Ann Rheum Dis, 71, 929-934.

[65] Umemura, S., Arima, H., Arima, S., Asayama, K., Dohi, Y., Hirooka, Y., Horio, T., Hoshide, S., Ikeda, S., Ishimitsu, T., Ito, M., Ito, S., Iwashima, Y., Kai, H., Kamide, K., Kanno, Y., Kashihara, N., Kawano, Y., Kikuchi, T., Kitamura, K., Kitazono, T., Kohara, K., Kudo, M., Kumagai, H., Matsumura, K., Matsuura, H., Miura, K., Mukoyama, M., Nakamura, S., Ohkubo, T., Ohya, Y., Okura, T., Rakugi, H., Saitoh, S., Shibata, H., Shimosawa, T., Suzuki, H., Takahashi, S., Tamura, K., Tomiyama, H., Tsuchihashi, T., Ueda, S., Uehara, Y., Urata, H., \& Hirawa, N. (2019) The Japanese Society of Hypertension Guidelines for the Management of Hypertension (JSH 2019). Hypertens Res, 42, 1235-1481.

[66] INRA (2021) Phenol-Explorer database [Internet]. Available from: http://phenol-explorer.eu/compounds.

[67] Yamakita, J., Yamamoto, T., Moriwaki, Y., Takahashi, S., Tsutsumi, Z., \& Higashino, K. (1998) Effect of Tofu (bean curd) ingestion and on uric acid metabolism in healthy and gouty subjects. Adv Exp Med Biol, 431, 839-842.

[68] Liu, J., Sun, L. L. He, L. P., Ling, W. H., Liu, Z. M., \& Chen, M (2014) Soy food consumption, cardiometabolic alterations and carotid intima-media thickness in Chinese adults. Nutr Metab Cardiovasc Dis, 24, 1097-1104. 
[69] Esmaillzadeh, A., \& Azadbakht, L. (2012) Legume consumption is inversely associated with serum concentrations of adhesion molecules and inflammatory biomarkers among Iranian women. J Nutr, 142, 334-339.

[70] Bitzer, Z. T., Wopperer, A. L., Chrisfield, B. J., Tao, L., Cooper T. K., Vanamala, J., Elias, R., Hayes, J. E., \& Lambert, J. D. (2017) Soy protein concentrate mitigates markers of colonic inflammation and loss of gut barrier function in vitro and in vivo. J Nutr Biochem, 40, 201-208.

[71] Souza, R. G., Gomes, A. C., Naves, M. M., \& Mota, J. F. (2015) Nuts and legume seeds for cardiovascular risk reduction: scientific evidence and mechanisms of action. Nutr Rev, 73, 335-347.

[72] Bazzano, L. A., He, J., Ogden, L. G., Loria, C., Vupputuri, S., Myers, L., \& Whelton, P. K. (2001) Legume consumption and risk of coronary heart disease in US men and women: NHANES I Epidemiologic Follow-up Study. Arch Intern Med, $161,2573-2578$.

[73] Unger, T., Borghi, C., Charchar, F., Khan, N. A., Poulter, N. R., Prabhakaran, D., Ramirez, A., Schlaich, M., Stergiou, G. S., Tomaszewski, M., Wainford, R. D., Williams, B., \& Schutte, A. E. (2020) 2020 International Society of Hypertension global hypertension practice guidelines. Hypertension, 75, 1334-1357.

[74] Wang, C., Guo, X-F., Yang, T., Zhao, T. \& Li, D. (2021) Nut intake and hyperuricemia risk in young adults. Public Health Nutr, 15, 1-19.

[75] Saag, K. G., \& Choi, H. K. (2006) Epidemiology, risk factors, and lifestyle modifications for gout. Arthritis Res Ther, 8 (suppl 1), S2.

[76] Schlesinger, N. (2005) Dietary factors and hyperuricemia. Curr Pharm Des, 11, 4133-4138.

[77] Chan, M., Kelly, J., \& Tapsell, L. (2017) Dietary modeling of foods for advanced CKD based on general healthy eating guidelines: What should be on the plate? Am J Kidney Dis, 69, 436-450.

[78] Blau, L. W. (1950) Cherry diet control for gout and arthritis. Tex Rep Biol Med, 8, 309-311.

[79] Jacob, R. A., Spinozzi, G. M., Simon, V. A., Kelley, D. S., Prior, R. L., Hess-Pierce, B., \& Kader, A. A. (2003) Consumption of cherries lowers plasma urate in healthy women. J Nutr, 133, 1826-1829.

[80] Haidari, F., Mohammad Shahi, M., Keshavarz, S. A., \& Rashidi, M. R. (2009) Inhibitory effects of tart cherry (prunus cerasus) juice on xanthine oxidoreductase activity and its hypouricemic and antioxidant effects on rats. Mal J Nutr, 15, 53-64.

[81] Martin, K. R., Bopp, J., Burrell, I., \& Hook, G. (2011) The effect of $100 \%$ tart cherry juice on serum uric acid levels, biomarkers of inflammation and cardiovascular disease risk factors. FASEB J, 25 (Meeting Abstract Supplement), 339.2 .

[82] Usharani, P., Nutalapati, C., Pokuri, V. K., Kumar, C. U., \& Taduri, G. (2016) A randomized, double-blind, placebo-, and positive-controlled clinical pilot study to evaluate the efficacy and tolerability of standardized aqueous extracts of Terminalia chebula and Terminalia bellerica in subjects with hyperuricemia. Clinical Pharmacology: Advances and Applicvations, 8, 51-59.
[83] Zhang, Y., Neogi, T., Chen, C., Chaisson, C., Hunter, D. J., \& Choi, H. K. (2012) Cherry consumption and decreased risk of recurrent gout attacks. Arthritis Rheum, 64, 4004-4011.

[84] Schlesinger, N., Rabinowitz, R., \& Schlesinger, M. (2012) Pilot studies of cherry juice concentrate for gout flare prophylaxis. J Arthritis, 1, 1-5.

[85] Jakše, B., Jakše, B., Pajek, M., \& Pajek, J. (2019) Uric acid and plant-based nutrition. Nutrients, 11, 1736.

[86] Ikizler, T. A., Burrowes, J. D., Byham-Gray, L. D., Campbell, K. L., Carrero, J-J., Chan, W., Fouque, D., Friedman, A. N., Ghaddar, S., Goldstein-Fuchs, D. J., Kaysen, G. A., Kopple, J. D., Teta, D., Wang, A. Y-M., \& Cuppari, L. (2020) KDOQI clinical practice guideline for nutrition in CKD: 2020 update. Am J Kidney Dis, 76, S1-S107.

[87] Nutrition and Your Health. 1990, Dietary Guidelines for American. 3 rd ed. U.S. Department of Agriculture, US Dept of Health and Human Services; 1990. Home and Garden Bulletin 232. Washington, D.C.

[88] Flynn, T. J., Cadzow, M., Dalbeth, N., Jones, D. B., Stamp, L. K., Hindmarsh, J. H., Todd, A. S., Walker, R. J., Topless, R., \& Merriman, T. R. (2015) Positive association of tomato consumption with serum urate: support for tomato consumption as an anecdotal trigger of gout flares. BMC Musculoskelet Disord, 16, 196.

[89] Vinha, A. F., Barreira, S. V., Costa, A. S., Alves, R. C., \& Oliveira, M. B. P. (2014) Pre-meal tomato (Lycopersicon esculentum) intake can have anti-obesity effects in young women? Int J Food Sci Nutr, 65, 1019-1026.

[90] Lee, C-Y. J., Isaac, H. B., Huang, S. H., Long, L. H., Wang, H., Gruber, J., Ong, C. N., Kelly, R. P., \& Halliwell, B. (2009) Limited antioxidant effect after consumption of a single dose of tomato sauce by young males, despite a rise in plasma lycopene. Free Radic Res, 43, 622-628.

[91] Abete, I., Perez-Cornago, A., Navas-Carretero, S. Bondia-Pons, I., Zulet, M. A., \& Martinez, J. A. (2013) A regular lycopene enriched tomato sauce consumption influences antioxidant status of healthy young subjects: A crossover study. J Funct Foods, 5, 28-35.

[92] Engelhard, Y. N., Gazer, B., \& Paran, E. (2006) Natural antioxidants from tomato extract reduce blood pressure in patients with grade-1-hypertenaion: A double-blind, placebo-controlled pilot study. Am Heart J, 151, 100.

[93] Jacob, K., Periago, M. J., Bohm, V., \& Berruezo, G. R. (2008) Influence of lycopene and vitamin $\mathrm{C}$ from tomato juice on biomarkers of oxidative stress and inflammation. Br J Nutr, 99, 137-146.

[94] Cao, G., Russell, R. M., Lischner, N., \& Prior, R. (1998) Serum antioxidant capacity is increased by consumption of strawberries, spinach, red wine or vitamin $\mathrm{C}$ in elderly women. J Nutr, 128, 2383-2390.

[95] Kaneko, K., Aoyagi, Y., Fukuuchi, T., Inazawa, K., \& Yamaoka, N. (2014) Total purine and purine base content of common foodstuffs for facilitating nutritional therapy for gout and hyperuricemia. Biol Pharm Bull, 37, 709-721.

[96] Burton Goldberg Group. (1994) Alternative Medicine: The Definitive Guide, Future Medicine Publishing Co., Puyallup, WA. 
[97] Sánchez-Moreno, C., Cano, M. P., de Ancos, B., Plaza, L., Olmedilla, B., Granado, F., \& Martín, A. (2004) Consumption of high-pressurized vegetable soup increases plasma vitamin C and decreases oxidative stress and inflammatory biomarkers in healthy humans. J Nutr, 134, 3021-3025.

[98] Türk, C., Neisius, A., Petrik, A., Seitz, C., Skolarikos, A., Thomas, K., Donaldson, J. F., Drake, T., Grivas, N., \& Ruhayel, Y. (2018) EAU Guidelines on Urolithiasis. European Association of Urology 2018. EAU Guidelines. Edn. Presented at the EAU Annual Congress London 2018. ISBN 978-94-92671-01-1. EAU Guidelines office, Arnhem, The Netherlands [Internet]. Available from: http://uroweb.org/guidelines/compilations-of-all-guidelines /.

[99] World Health Organization (2007) Prevention of cardiovascular disease. Guidelines for assessment and management of cardiovascular risk. pp. 1-86. WHO Press. Geneva, Switzerland.

[100] Australian Government, Department of Health and Aging. The Go for 2 Fruit \& 5 Vegetables ${ }^{\mathrm{TM}}$ Campaign [Internet]. Available https://healthywa.wa.gov.au/Articles/F_I/Go-for-2-and-5.

[101] US Department of Agriculture. (2005) Dietary guidelines for Americans. Center for Nutrition Policy and Promotion, USDA. Washington, DC.

[102] The Ministry of Agriculture, Forestry and Fisheries. (2020) WASHOKU, traditional dietary cultures of the Japanese [Internet]. Available from: https://www.maff.go.jp/e/japan_food/washoku/pdf/wasyoku_e nglish.pdf.

[103] Costa-Bauza, A., Grases, F., Calvó, P., Rodriguez, A., \& Prieto, R. M. (2018) Effect of consumption of cocoa-derived products on uric acid crystallization in urine of healthy volunteers. Nutrients, 10, 1516.

[104] Grases, F., Rodriguez, A., \& Costa-Bauza, A. (2014) Theobromine inhibits uric acid crystallization. A potential application in the treatment of uric acid nephrolithiasis. PLoS ONE, 9, e111184.

[105] Basu, S., McKee, M., Galea, G., \& Stuckler, D. (2013) Relationship of soft drink consumption to global overweight, obesity, and diabetes: a cross-national analysis of 75 countries. Am J Public Health, 103, 2071-2077.

[106] Choi, J. W. J., Ford, E. S., Gao, X., \& Choi, H. K. (2008) Sugar-sweetened soft drinks, diet soft drinks, and serum uric acid level: The third national health and nutrition examination survey. Arthritis. Rheum, 59, 109-116.

[107] Merriman, T. R., Dalbeth, N., \& Johnson, R. J. (2014) Sugar-sweetened beverages, urate, gout and genetic interaction. Pac Health Dialog, 20, 31-38.

[108] Nguyen, S., Choi, H. K., Lustig, R. H., \& Hsu, C. Y. (2009) Sugar-sweetened beverages, serum uric acid, and blood pressure in adolescents. J Pediatr, 154, 807-813.

[109] Meneses-Leon, J., Denova-Gutiérrez, E., Castañón-Robles, S., Granados-Garcia, V., Talavera, J. O., Rivera-Paredez, B., Huitrón-Bravo, G. G., Cervantes-Rodriguez, M., Quiterio-Trenado, M., Rudolph, S. E., \& Salmerón, J. (2014) Sweetened beverage consumption and the risk of hyperuricemia in Mexican adults: a cross-sectional study. BMC Public Health, 14, 445.
[110] Bae, J., Chun, B. Y., Park, P. S., Choi, B. Y., Kim, M. K., Shin, M. H., Lee, Y. H., Shin, D. H., \& Kim, S. K. (2014) Higher consumption of sugar-sweetened soft drinks increases the risk of hyperuricemia in Korean population: The Korean Multi-Rural Communities Cohort Study. Semin. Arthritis Rheum, 43, 654-661.

[111] Ebrahimpour-Koujan, S., Saneei, P., Larijani, B., \& Esmaillzadeh, A. (2020) Consumption of sugar sweetened beverages and dietary fructose in relation to risk of gout and hyperuricemia: a systematic review and meta-analysis. Crit Rev Food Sci Nutr, 60, 1-10.

[112] Choi, H. K., Willett, W., \& Curhan, G. (2010) Fructose-rich beverages and the risk of gout in women. JAMA, 304, $2270-2278$

[113] Johnson, R. J., Nakagawa, T., Sánchez-Lozada, L. G., Shafiu, M., Sundaram, S., Le, M., Ishimoto, T., Sautin, Y. Y., \& Lanaspa, M. A. (2013) Sugar, uric acid, and the etiology of diabetes and obesity. Diabetes, 62, 3307-3315.

[114] Pham, N. M., Yoshida, D., Morita, M., Yin, G., Toyomura, K., Ohnaka, K., Takayanagi, R., \& Kono, S. (2010) The relation of coffee consumption to serum uric acid in Japanese men and women aged 49-76 years. J Nutr Metab, 2010, 930757.

[115] Choi, H. K., \& Curhan, G. (2007) Coffee, tea, and caffeine consumption and serum uric acid level: The third national health and nutrition examination survey. Arthritis Rheum, 57, 816-821.

[116] Kiyohara, C., Kono, S., Honjo, S., Todoroki, I., Sakurai, Y., Nishiwaki, M., Hamada, H., Nishikawa, H., Koga, H., Ogawa, S., \& Nakagawa, K. (1999) Inverse association between coffee drinking and serum uric acid concentrations in middle-aged Japanese males. Br J Nutr, 82, 125-130.

[117] Choi, H. K., Willett, W., \& Curhan, G. (2007) Coffee consumption and risk of incident gout in men: A prospective study. Arthritis Rheum, 56, 2049-2055.

[118] Choi, H. K., \& Curhan, G. (2010) Coffee consumption and risk of incident gout in women: the Nurses' Health Study. Am J Clin Nutr, 92, 922-927.

[119] Juraschek, S. P., Kowell, L. C., Miller, E. R., \& Gelber, A. C. (2013) Dose-response association of uncontrolled blood pressure and cardiovascular disease risk factors with hyperuricemia and gout. PLoS One, 8, e56546.

[120] Poole, R., Kennedy, O. J., Roderick, P., Fallowfield, J. A., Hayes, P. C., \& Parkes, J. (2017) Coffee consumption and health: umbrella review of meta-analyses of multiple health outcomes. BMJ, 359, j5024.

[121] Zhang Y, Yang T, Zeng C, Wei, J., Li, H., Xiong, Y. L., Yang, Y., Ding, X., \& Lei, G.: Is coffee consumption associated with a lower risk of hyperuricaemia or gout? A systematic review and meta-analysis. (2016) BMJ Open, 6, e009809.

[122] Panza, V. S., Wazlawik, E., Ricardo Schütz, G., Comin, L., Hecht, K. C., \& da Silva, E. L. (2008) Consumption of green tea favorably affects oxidative stress markers in weight-trained men. Nutrition, 24, 433-442.

[123] Bahorun, T., Luximon-Ramma, A., Gunness, T. K., Sookar, D., Bhoyroo, S., Jugessur, R. Reebye, D., Googoolye, K., Crozier, A., \& Aruoma, O. I. (2010) Black tea reduces uric acid and C-reactive protein levels in humans susceptible to cardiovascular diseases. Toxicology, 278, 68-74. 
[124] Teng, G. G., Tan, C. S., Santosa, A., Saag, K. G., Yuan, J. M., \& Koh, W. P. (2013) Serum urate levels and consumption of common beverages and alcohol among Chinese in Singapore. Arthritis Care Res, 65, 1432-1440.

[125] Li, X., Song, P., Li, J., Wang, P., \& Li, G. (2015) Relationship between hyperuricemia and dietary risk factors in Chinese adults: a cross-sectional study. Rheumatol Int, 35, 2079-1089.

[126] Choi, H. K., Mount, D. B., Reginato, A. M., American College of Physicians; American Physiological Society (2005) Pathogenesis of gout. Ann Intern Med, 143, 499-516.

[127] Towiwat, P., \& Li, Z. G. (2015) The association of vitamin C, alcohol, coffee, tea, milk and yogurt with uric acid and gout. Int J Rheum Dis, 18, 495-501.

[128] Kela, U., Vijayvargiya, R., \& Trivedi, C. P. (1980) Inhibitory effects of methylxanthines on the activity of xanthine oxidase. Life Sci, 27, 2109-2119.

[129] Tsai, Y. T., Liu, J. P., Tu, Y, K., Lee, M. S., Chen, P. R., Hsu, H. C., Chen, M. F., \& Chien, L. L. (2012) Relationship between dietary patterns and serum uric acid concentrations among ethnic Chinese adults in Taiwan. Asia Pac J Clin Nutr, 21, 263-270.

[130] Pérez-Jiménez, J. (2010) Identification of the 100 richest dietary sources of polyphenols an application of the Phenol-Explorer database. Eur J Clin Nutr, 64, Suppl 3, S112-120.

[131] European Food Safety Authority (EFSA). (2015) Scientific opinion on the safety of caffeine. EFSA Panel on Dietetic Products, Nutrition and Allergies (NDA). EFSA Journal, 13, 4102.
[132] All Japan Coffee Association (2021) Coffee of consumption in Japan [Internet]. Available from: http://coffee.ajca.or.jp/wp-content/uploads/2019/06/data04 20 19-06b.pdf.

[133] Soriano, L. C., Rothenbacher, D., Choi, H. K., \& Rodriguez, G. (2011) Contemporary epidemiology of gout in the UK general population. Arthritis Res Ther, 13, R39.

[134] van der Gaag, M. S., van den Berg, R., van den Berg, H., Schaafsma, G., \& Hendriks, H. F. (2000) Moderate consumption of beer, red wine and spirits has counteracting effects on plasma antioxidants in middle-aged men. Eur J Clin Nutr, 54, 586-591.

[135] Yamamoto, T., Moriwaki, Y., Ka, T., Inokuchi, T., Takahashi, S., Tsutsumi, Z., Fukuchi, M., \& Hada, T. (2004) Effect of purine-free low-malt liquor (happo-shu) on the plasma concentrations and urinary excretion of purine bases and uridine-comparison between purine-free and regular happo-shu. Horm Metab Res, 36, 231-237.

[136] Choi, H. K., \& Curhan, G. (2004) Beer, liquor, and wine consumption and serum uric acid level; The Third National Health and Nutrition Examination Survey. Arthritis Rheum, 51, 1023-1029.

[137] Choi, H. K., Atkinson, K., Karlson, E. W., Willett, W., \& Curhan, G. (2004) Alcohol intake and risk of incident gout in men: a prospective study. Lancet, 363, 1277-1281.

[138] Gaffo, A. L., Roseman, J. M., Jacobs, D. R. Jr., Lewis, C. E., Shlkany, J. M., Mikuls, T. R., Jolly, P. E., \& Saag, K. G. (2010) Serum urate and its relationship with alcoholic beverage intake in men and women: findings from the Coronary Artery Risk Development in Young Adults (CARDIA) cohort. Ann Rheum Dis, 69, 1965-1970. 